\title{
Migration of aerobic bacteria from the duodenum to the pancreas with tumors: a mechanistic understanding
}

Hiroaki Shirai ( $\sim$ hs7796@keio.jp )

Keio University

Cocoro Ito

Keio University

Kosuke Tsukada

Keio University

\section{Research Article}

Keywords: $\mathrm{pH}$ taxis, microfluidics, mathematical modeling, pancreatic cancer, microbiome

Posted Date: October 1st, 2021

DOl: https://doi.org/10.21203/rs.3.rs-948107/v1

License: (c) (i) This work is licensed under a Creative Commons Attribution 4.0 International License.

Read Full License 


\section{Migration of aerobic bacteria from the duodenum to the pancreas with \\ 2 tumors: a mechanistic understanding}

3

$4 \quad$ Hiroaki Shirai ${ }^{*}$ Cocoro Ito $^{\mathrm{b}}$, Kosuke Tsukada ${ }^{\mathrm{a}, \mathrm{b}}$

5 aGraduates School of Science and Technology, Keio University, 3-14-1 Hiyoshi Kohoku-ku,

6 Yokohama-shi, Kanagawa, Japan 223-8522

$7 \quad$ bFaculty of Science and Technology, Keio University

8 Hiroaki Shirai.

$9 \quad$ Email: hs7796@keio.jp

11 Author Contributions: Hiroaki Shirai performed the entire work, wrote the manuscript,

12 performed microfluidic experiments, and performed mathematical modeling. Cocoro Ito designed

13 and fabricated the microfluidic device. Kosuke Tsukada is PI of the laboratory, obtained funding,

14 provided research equipment, and managed the laboratory.

15 Keywords: $\mathrm{pH}$ taxis, microfluidics, mathematical modeling, pancreatic cancer, microbiome.

\section{Abstract}

17 More aerobic bacteria are found in the pancreas with tumors than in the healthy pancreas. We

18 provide a mechanistic understanding of the migration of intestinal bacteria from the duodenum to

19 the pancreas with tumors. Mathematical models of migration of aerobic bacteria from the 20 duodenum to the pancreas with tumors in the hepatopancreatic duct were developed. In addition,

21 the behaviors of GFP E. coli under a pH gradient in a microfluidic device were analyzed. Moreover,

22 upstream migrations of Pseudomonas fluorescens against flow were measured in a 
23 polydimethylsiloxane (PDMS) T-shaped cylinder mimicking a pancreatic duct. The simulated 24 bacterial concentration of the pancreas with tumors was higher than that of the healthy pancreas 25 and agreed reasonably well with the literature. Migration of aerobic bacteria in the hepatopancreatic 26 duct is counteracted by bile and pancreatic juice flow but facilitated greatly by bacterial pH taxis 27 from lower $\mathrm{pH}$ in duodenum fluid toward slightly alkaline $\mathrm{pH}$ in pancreatic juice, favorable for them.

28 Migration of bacteria to the pancreas with tumors is made easier by solid tumors on the pancreatic 29 duct, which compresses the pancreatic duct and thus reduces the fluid flow rate. On the other hand,

30 GFP E. coli migrated under the $\mathrm{pH}$ gradient in a microfluidic device from acidic areas toward neutral 31 or slightly alkaline $\mathrm{pH}$, validating $\mathrm{pH}$ taxis. Furthermore, Pseudomonas fluorescens migrated 32 upstream from hydrochloride solution but not from bicarbonate solution against bicarbonate flow at $33>20 \mu \mathrm{m} / \mathrm{s}$, with an advancing velocity of approximately $60 \mu \mathrm{m} / \mathrm{s}$, validating the models (244 words).

36 Main Text

\section{Introduction}

Effective treatment against pancreatic cancer with a five-year survival rate of $5-10 \%$ is urgent (1). The interactions between cancer and bacteria have widely been accepted, such as the

41 roles of gut microbes in immunotherapy(2). The pancreas, adjacent to and connected via the 42 pancreatic duct to the duodenum, a part of the small intestine with abundant intestinal bacteria, 43 provides a unique niche for cancer researchers (3-14), including a link between the oral 44 microbiome and risk of pancreatic cancer(3), bacteria found in pancreatic cystic fluid (4), bacterial 45 infection in the pancreas with pancreatitis and its association with cancer risk $(5,6)$, roles in 46 carcinogenesis $(7,8)$, and bacteria in tumors affecting cancer treatment $(9-14)$. For example, 47 human pancreatic ductal adenocarcinomas (PDACs) contain aerobic bacteria at higher levels than 48 healthy pancreases $(10,12)$ (Table S1), commonly favoring neutral $\mathrm{pH}$, such as Pseudomonas(15), 49 Citrobacter(16), Klebsialla I(17), and Streptococcus(18). These bacteria in tumors contribute to 50 treatment (10-14); for example, Gammaproteobacteria found in pancreatic cancer induce 
51 resistance to the widely used chemotherapeutic drug gemcitabine(10). Antibiotic treatment was

52 associated with the efficacy of gemcitabine in mice(10) and in the clinic (19, 20). On the other hand,

53 PDAC long-term survivors displayed diverse tumor microbes and immune activation (13).

54 Moreover, aggressive tumors harbor distinctive microbial communities (8).

55 Despite the roles of intratumoral bacteria, the mechanisms of bacterial migration into pancreatic

56 tumors are poorly understood. A mechanistic understanding of bacterial migration from the

57 duodenum into the pancreas is critical for understanding pancreatic disease and thus improving

58 therapeutic outcomes. Previous findings demonstrated that bacterial DNA profiles in the pancreas

59 of the same subjects were similar to those in the duodenum tissue(21). In addition, orally

60 administered E. coli was found in pancreatic tumors in mice (12), implying migration from the

61 duodenum to the pancreas (figure $1 \mathrm{a}, \mathrm{b}$ ).

62

63 Literature about mathematical modeling and experimental studies of bacterial penetration in the

64 gastrointestinal tract

65 Mathematical modeling of bacterial penetration in the human gastrointestinal tract is missing in

66 the literature. Bacterial penetration into meat and leafy vegetables with sessile drops were

67 mathematically modeled previously (22-24). Bacterial migration in colon mucus and to the

68 epithelial layer was investigated(25). The effect of chemotaxis on host infection and pathogenicity

69 was also reviewed (26). On the other hand, upstream swimming of Escherichia coli was analyzed

70 (27-29). Diao and coworkers developed a three-channel microfluidic device to analyze bacterial

71 chemotaxis(30).

72

$73 \quad$ Missing mechanistic understanding

74 Despite the aforementioned advances, a mechanistic understanding of the migration of aerobic

75 bacteria from the duodenum into the pancreas with tumors has not been achieved. In particular,

76 since bacterial invasion from the intestine into the pancreas is inhibited by defense systems such

77 as bile flow and the high-pressure zone at the sphincter of Oddi, a muscle situated at the junction 
78 of the duodenum and pancreatic duct (31) (figure 2), it has been unclear what factor makes a

79 difference in bacterial migration into heathy pancreas and pancreas with tumors.

81 Objectives of this work

82 The hypotheses of this work are twofold: (1) migration of aerobic bacteria from the duodenum into

83 the pancreas is explained by a mathematical model that includes bacterial random motility, the flow

84 of pancreatic juice and bile, $\mathrm{pH}$ taxis, aerotaxis to higher oxygen and away from carbon dioxide,

85 and (2) bacterial migration from the duodenum to the pancreas in the hepatopancreatic duct is

86 experimentally modeled in a T-shaped cylinder, mimicking the pancreatic duct. This work first

87 provides simulated migrations of aerobic bacteria from the duodenum to the pancreas with tumors.

88 Second, the $\mathrm{pH}$-tactic behaviors of GFP E. coli were demonstrated in a $\mathrm{pH}$-gradient reproducible

89 microfluidic device. Finally, $\mathrm{pH}$-tactic migrations of $P$. fluorescens from the duodenum to pancreas

90 were measured to validate the models. This work aims to understand how each factor and its

91 combination with others contribute to the migration of aerobic bacteria from the duodenum to the

92 pancreas with tumors.

93

\section{Results}

96 Migration of aerobic bacteria from duodenal fluid into the pancreas is driven by $\mathrm{pH}$ taxis

97 The simulated $\mathrm{pH}$ in the hepatopancreatic duct increased greatly from the duodenum with lower $98 \mathrm{pH}$ to the pancreas at neutral or slightly alkaline $\mathrm{pH}$ (figure 3 green, eqn. 17) since the diffusion of

99 gastric acid into the hepatopancreatic duct is not just counteracted by bile and pancreatic juice flow

100 but also neutralized by bicarbonate in pancreatic juice (eqn. 17) (figure 3). Carbon dioxide is 101 generated as a byproduct of neutralization at the duodenum (eqn. 17) (figure 3 blue). The simulated

$102 \mathrm{pH}$ in the pancreas at 7.6 (figure 4 green) agrees reasonably well with the literature that pancreatic 103 juice has a $\mathrm{pH}$ of $8.0-8.3$ and liver bile has $\mathrm{pH}$ at 7.8 (38).

104 The migration of aerobic bacteria in the hepatopancreatic duct from the duodenum into the

105 pancreas was simulated (Figures 4, 7, 1S). Factors that influence bacterial transport are 
106 summarized in Table 1. The simulated bacterial concentration in the healthy pancreas (figure 4 107 blue) was lower than that in the literature (figure 4 orange)(12). However, the bacterial amount 108 estimated using the typical weight of the pancreas at $80 \mathrm{~g}$ at $3.2 \mathrm{CFU}$ seems consistent with the 109 literature that $15 \%$ of healthy pancreas contained detectable bacteria (10). Bacteria did not migrate 110 into the pancreatic duct due to motility alone, even at the periphery of duct, where fluid flow velocity

111 is lower (Figure S1b black dotted). However, bacterial $\mathrm{pH}$-taxis under the $\mathrm{pH}$-gradient at the T112 junction (figure 3 green) facilitates migration from acidic duodenum fluid toward pancreatic duct 113 containing pancreatic juice at slightly alkaline $\mathrm{pH}$, more favorable for them (figures S1a, $\mathbf{b}$ blue and

114 green). Moreover, migration was slightly facilitated by aerotaxis of aerobic bacteria away higher 115 carbon dioxide concentrations at the duodenum (Figures 3 blue, S1b blue and red).

117 Measured migration of GFP E. coli under a $\mathrm{pH}$ gradient in a microfluidic device validates $\mathrm{pH}$ taxis 118 A steady pH gradient was generated in a two-laminar flow-based PDMS microfluidic device (figure $1195 \mathbf{a}$ ), where the $\mathrm{pH}$ changed from 5-5.5 on the top to 8-9 at the bottom (figures $5 \mathbf{a}, \mathrm{S} 2$ ). As a control, 120 GFP E. coli migrated little without a gradient (figure $5 \mathbf{d}$, e black). Under this $\mathrm{pH}$ gradient, the $\mathrm{pH}$ 121 tactic behaviors of GFP E. coli were analyzed (figure 5). When GFP E. coli were included under 122 the $\mathrm{pH}$ gradient (figure 5a) in either the upper (figure 5b) or bottom inlets (figure 5c), GFP E. coli 123 migrated vertically from the upper channel with a lower $\mathrm{pH}$ toward the lower channel with a slightly 124 alkaline $\mathrm{pH}$ (figures $5 \mathbf{b}$, c, e blue and orange), showing $\mathrm{pH}$-tactic behaviors. Note that carbon 125 dioxide was generated at the top channel $\left(0.7 \mathrm{mmol} \mathrm{I}^{-1}\right)$ due to neutralization (figure S3), where $E$. 126 coli was attracted toward higher carbon dioxide (32). Thus, a higher bacterial concentration in the 127 lower channel, where the carbon dioxide concentration is lower (Figures $\mathbf{5 b}$, $\mathbf{c}$, orange and green, 128 S3), still assures $\mathrm{pH}$ taxis.

130 Measured upstream migration of $P$. fluorescens in a T-shaped cylinder validates the models

131 Upstream migrations of Pseudomonas fluorecens in a four-millimeter T-shaped cylinder against 132 the flow of bicarbonate at $20 \mu \mathrm{l} / \mathrm{min}$, in equilibrium to $5 \%$ carbon dioxide (figure S4), were measured 133 to validate the models (movie S1). Pseudomonas fluorescens was chosen here, as Pseudomonas 
134 was one of the most commonly found strains in pancreatic cancer (10) and can be seen under UV 135 light using their intrinsic fluorescence. A lower flow rate of $20 \mu \mathrm{l} / \mathrm{min}$ was chosen to easily observe

136 bacterial migration under flow conditions. $P$. fluorescens migrated upstream against bicarbonate

137 flow with a maximum fluid velocity of $52 \mu \mathrm{m} / \mathrm{s}$ from hydrochloride solution at pH 5-6, with advancing 138 velocity of approximately $60 \mu \mathrm{m} / \mathrm{s}$ (figure 6 , S5a, movies $\mathrm{S} 1$ and 2 left). These upstream migrations

139 of $P$. fluorescens are caused by $\mathrm{pH}$ taxis at the $\mathrm{T}$-junction, where $\mathrm{pH}$ increases dramatically (figure 140 8a), pushing them from acidic areas toward neutral or slightly alkaline $\mathrm{pH}$. This $\mathrm{pH}$ taxis wanes fluid 141 flow in the cylinder, probably near the wall, where fluid velocity is lower (movies S1 and S2 left).

142 Migration immediately close to the T-junction is swift, probably due to a greater $\mathrm{pH}$ and $\mathrm{CO}_{2}$ 143 gradient (figure 6a), compared with lower advancement in the areas far from the junction (figure $1446 \mathbf{a}$, S5a, movies S1 and S2 left). P. fluorescens in bicarbonate did not migrate against flow due to 145 motility alone (figure S5b, movie S2 right). These results are consistent with the simulation results 146 (Figure S6, movies S3 and 4).

148 Obstructed pancreatic and bile ducts in the pancreas with tumors increase migration

149 The simulated bacterial concentration in the pancreas with tumors (figure 4 gray) was over 100 150 times higher than that in the healthy pancreas (figure 4 blue) and agreed reasonably well with the 151 literature (figure 4 yellow). This is also consistent with findings that $83 \%$ of pancreatic tumors 152 contained detectable bacteria(10). Pancreatic ductal adenocarcinoma (PDAC), which occurs at the 153 pancreatic duct, compresses the pancreatic duct, reducing pancreatic juice flow rates (33-35). 154 Moreover, $70 \%$ of pancreatic cancer patients have biliary obstruction at the time of diagnosis (36, 155 37). The reduced pancreatic juice and bile flow rates led to easier migration toward the pancreas 156 (Figures 7 and S7). In addition, the bacterial concentration in the pancreas with tumors was ellipse- 
157 shaped with a lower concentration along the pancreatic duct and a higher concentration along the

158 duodenum wall due to reflux of bacteria to the duct (figure S7).

159

160 Aerotaxis of aerobic bacteria to higher oxygen at the duodenum affects migration less

161 Oxygen dissolved in duodenal fluid diffuses into both the hepatopancreatic duct and duodenal wall

162 toward the pancreas with the tumor, where the oxygen concentration is lower, due to oxygen

163 consumption by cancer cells (figure S8). Note that diffusion in the duct is inhibited by flow, while

164 that in the duodenum wall is not inhibited but by the physical barrier of the wall (figure S8). Oxygen

165 in the duodenal wall surrounding the hepatopancreatic duct diffuses into the duct through the wall

166 of the duct (eqn. 5) (figure S8). Aerotaxis of aerobic bacteria toward the duodenum with higher

167 oxygen (figure S8) had little effect on migration (figure S9). This is probably because aerotaxis to

168 higher oxygen at the duodenum is outweighed by both aerotaxis away from higher carbon dioxide

169 concentration and $\mathrm{pH}$-taxis to neutral $\mathrm{pH}$ in the pancreas (figure S9). Thus, aerobic bacteria,

170 showing aerotaxis to higher oxygen, even migrated into the pancreas with the tumor (figure S9

171 blue).

172

173 Parametric sensitivity analysis

174 Maximum fluid velocity greatly affects bacterial migration into the pancreas (figure 8). The $\mathrm{pH}$ of

175 duodenal fluid also has a great effect on migration into the pancreas since increased $\mathrm{pH}$ reduces

176 the $\mathrm{pH}$ gradient between the duodenum and pancreatic duct, which in turn reduces $\mathrm{pH}$ tactic-driven

177 migration (figure 8). The random motility coefficient has no effect on penetration, although the $\mathrm{pH}-$

178 tactic sensitivity coefficient greatly affects penetration (figure 8). Increased permeability of the

179 hepatopancreatic duct also increased migration to the pancreas by increasing efflux from the duct

180 to pancreatic tissues (figure 8).

181

182 Discussion

183 Factors contributing to faster $\mathrm{pH}$-tactic velocity 
184 The measured pH-tactic velocity in a T-shaped cylinder is over $50 \mu \mathrm{m} / \mathrm{s}$ (figure $6 \mathrm{~b}, \mathrm{~S} 5 \mathrm{~b}$ ), much

185 faster than the typical chemotactic velocity at $10 \mu \mathrm{m} / \mathrm{s}$. This may be due to the following reasons.

186 First, the gradient under flow is made greater since the flow inhibits diffusion (figure 3 green).

187 Second, an increase in $\mathrm{pH}$ leads to exponential decreases in hydrogen ion concentration. Thus,

188 chemotactic ( $\mathrm{pH}$-tactic) velocity (Keller-Segel model, eqn. 9), influenced by the concentration

189 gradient, is faster. Note that the hydrodynamic properties of bacteria such as rod-shaped E. coli

190 may also contribute to faster upstream migration than simulated bacteria (27).

192 Pathway for migration of aerobic bacteria to pancreatic tumors

193 The probable pathway for migration of aerobic and motile bacteria in the duodenum into the

194 pancreatic tumor is divided into the following four: (i) at the T-junction of duodenum and pancreatic

195 duct, i.e., high pressure zone of the Sphincter of Oddi, driven by $\mathrm{pH}$-taxis under a sharp $\mathrm{pH}$-gradient

196 (figures 3 green, 6a, 7), (ii) in the hepato-pancreatic duct, driven by $\mathrm{pH}$-taxis under a milder gradient

197 (figure 3, 6a, 7), (iii) through the ductal wall out to pancreatic tissues (figure 7 and S2), (iv) in

198 pancreatic tissue (interstitium) and tumor (figure 7, S7). The first step is made easier in cancer

199 patients with obstructions of the bile and pancreatic duct by reducing flow velocity. The second step

200 is in the duodenum wall. The third step is probably driven by the concentration difference between

201 the duct and the interstitium (eqn. 6). The last step is migration in tissues, where bacterial motility

202 is inhibited by the geometric barrier of the interstitium (porous medium) but not by the flow. As a

203 result, bacterial motility in tumors is reduced due to densely packed interstitium (40). Note that

204 bacteria in healthy tissues are probably eliminated by the immune system, while those in tumors

205 are not due to the suppressed immune system (41).

Origins of bacteria in pancreatic tumor

208 These results may help controversy over the origins of bacteria found in pancreatic tumors. The

209 proposed origin in the literature includes the duodenum via the pancreatic duct and large intestine

210 through the portal vein (11). It is noteworthy that pancreatic cancer contains immotile bacteria

211 (Table S1), which do not show motility or pH-taxis, or migrate into the pancreas even in the reduced 
212 flow (Figure 7). Thus, the latter route is not neglected. Moreover, the intestinal barrier in patients

213 with obstructive jaundice is impaired, which is frequently accompanied by pancreatic cancer(36);

214 thus, bacterial translocation via the bloodstream is promoted (42). On the other hand, bacterial

215 colonization in the pancreas was not detected in a mouse model with defective intestinal

216 permeability with increased permeability by Campylobacter infection (5). However, Pseudomonas

217 putida, which is motile and highly aerobic, was the most common strain in pancreatic tumors (10)

218 (Table S1), with a higher presence of Pseudomonas in cancer patients (21), which agrees with

219 results showing that aerobic bacteria migrate upstream in the hepatopancreatic duct toward the

220 pancreas with $\mathrm{pH}$ taxis (figures $6,7, \mathrm{~S} 5$ ).

221

222 This mechanistic understanding is relevant to all possible transport phenomena between 223 duodenum and pancreas, such as a link between oral microbiome and risk of pancreatic cancer (3,

$2244,43,44)$, roles of bacteria in carcinogenesis $(7,8)$, bacterial infection on common bile duct $(37)$

225 and in pancreas with pancreatitis and its association with cancer risk (6), and bacteria in pancreatic 226 tumor affecting chemo- or immunotherapy $(10,12)$ (figure 9$)$. For example, possible entry of oral 227 bacteria in the duodenum into the healthy pancreas (figure S1) is associated with cancer risk $(3,4$, 228 43, 44). Moreover, our results are also relevant to migration routes into the pancreas with 229 pancreatitis (6). The hypothetical mechanisms for migration to pancreas with pancreatitis in 230 literature include hematogenous route via the circulation, transmural migration through the colonic 231 bowel wall either to the pancreas (translocation), via the biliary duct system, and from the 232 duodenum via the main pancreatic duct. (6). On the other hand, pancreatitis is followed by 233 insufficiency of bicarbonate secretion (6), leading to greater gastric acidification(45). Acidified 234 duodenum increases the $\mathrm{pH}$ gradient between the duodenum and the pancreas and thus migration 235 (figure 8). This is also consistent with the literature that most bacteria in the pancreas with 236 pancreatitis are aerobic (or facultative anaerobes), which prefer aerobic conditions in the 237 duodenum. On the other hand, compressed pancreatic and bile ducts are probably attributed to 238 solid stress of tumors due to dense extracellular matrix of fibrillary collagen and swelling hyaluronan 239 (46, 47). On the other hand, reducing bacterial migration into the pancreas with tumors (figure 8) 
240 may help antibiotic strategies improve the efficacy of gemcitabine(10,19, 20). Moreover, clinical

241 translation of the fecal microbial transplant (FMT) strategy to directly or indirectly influence the

242 tumor microbiome $(17,48)$ might benefit.

244 3. Conclusion

245 A mechanistic understanding of bacterial migration from the duodenum into the pancreas is

246 provided (figure 10). The migration of bacteria into the pancreas in the hepatopancreatic duct

247 seems to depend on a balance between pancreatic juice and bile flow in the duct as convection

248 (this reduces migration) and bacterial $\mathrm{pH}$ taxis away from the duodenum with a lower $\mathrm{pH}$ toward

249 the pancreas at neutral or slightly alkaline $\mathrm{pH}$. An imbalance of this (for example, reduced flow in

250 tumor) leads to increased migration. Mathematical modeling predicted bacterial migration into the

251 pancreas with tumors. The simulated bacterial concentration in the pancreas with tumors agreed

252 reasonably well with the literature. The $\mathrm{pH}$-tactic behaviors from acidic areas toward neutral $\mathrm{pH}$

253 were validated in a microfluidic study. The mathematical models were further validated by

254 measuring upstream migrations of bacteria under flow conditions.

258 4. Mathematical modeling of migration of aerobic bacteria from the duodenum to the pancreas 259 with tumors

Transports of bacteria and oxygen, bicarbonate, carbon dioxide, and hydrogen ion with

261 reactions in the hepatopancreatic duct were mathematically modeled. An anatomical schematic of 262 the upper gastrointestinal tract modeled is described in figures $1 \mathrm{a}$ and $1 \mathrm{~b}$. The geometry of the 263 axisymmetric cylindroid was used for hepatopancreatic duct, duodenum walls, and pancreas 264 tissues (figure 1c). Aerobic bacteria favoring neutral $\mathrm{pH}$, such as Pseudomonas, were used, as 265 they are typically bacterial strains found in pancreatic cancer(10). A list of the factors included in 
266 the modeling is shown in Table 1. The details of the modeling follow. The parameter list is provided in Table S2.

270 modeled using a diffusion-advection equation that includes bacterial motility, aerotaxis to oxygen,

271 aerotaxis away from carbon dioxide $\mathrm{pH}$ taxis, and pancreatic juice and bile flow (convection), as

272 described in the following governing equation:

$$
\begin{aligned}
& \frac{\partial b}{\partial t}=\underbrace{\mu_{e f f}\left(\frac{\partial^{2} b}{\partial x^{2}}+\frac{\partial^{2} b}{\partial r^{2}}+\frac{1}{r} \frac{\partial b}{\partial r}\right)}_{\text {motility }} \underbrace{\left\{\frac{\partial}{\partial x}\left(V_{a}^{x} b\right)+\frac{\partial}{\partial r}\left(V_{a}^{r} b\right)+\frac{1}{r}\left(V_{a}^{r} b\right)\right\}}_{\text {aerotaxis to oxygen }} \underbrace{\left\{\frac{\partial}{\partial x}\left(V_{c}^{x} b\right)+\frac{\partial}{\partial r}\left(V_{c}^{r} b\right)+\frac{1}{r}\left(V_{c}^{r} b\right)\right\}}_{\text {aerotaxis away from carbon dioxide }} \\
& \underbrace{-\left\{\frac{\partial}{\partial x}\left(V_{p H}^{x} b\right)+\frac{\partial}{\partial r}\left(V_{p H}^{r} b\right)+\frac{1}{r}\left(V_{p H}^{r} b\right)\right\}}_{\text {pH-taxis }} \underbrace{-\frac{\partial}{\partial x}\left(v_{h} b\right)}_{\begin{array}{c}
\text { bile and } \\
\text { pancreatic juice flow }
\end{array}}
\end{aligned}
$$

$274 b\left[\mathrm{CFU} \mathrm{ml}{ }^{-1}\right]$ is bacterial concentration, $\mu_{\text {eff }}\left[\mathrm{m}^{2} \mathrm{~s}^{-1}\right]$ is effective random motility coefficient of 275 bacteria, $V_{a}$ and $V_{c}\left[\mathrm{~m} \mathrm{~s}^{-1}\right]$ is aerotactic velocity to oxygen and carbon dioxide, respectively, $V_{p H}[\mathrm{~m}$ $\left.276 \mathrm{~s}^{-1}\right]$ is $\mathrm{pH}$-tactic velocity, and $v_{h}\left[\mathrm{~m} \mathrm{~s}^{-1}\right]$ is the fluid flow velocity in hepato-pancreatic duct.

277 Superscripts of $x$ and $r$ indicate the direction of aerotactic and $\mathrm{pH}$ taxis. The growth term was not 278 included here, as the period for bacterial migration (less than ten hours) is in general shorter than 279 bacterial growth (>10 h). Aerobic bacteria that respire only in aerobic conditions with an oxygen 280 substrate with carbon dioxide as a byproduct show aerotaxis to higher oxygen and toward lower 281 carbon dioxide, which were modeled. Chemotactic terms are typically modeled in convective terms 282 in the Keller-Segel model (50). A simplified one-dimensional model of eqn. 1 is provided in 283 supporting information. Each term will be described below in depth. 
288 coefficient, $\boldsymbol{\mu}_{\text {eff }}\left[\mathrm{m}^{2} \mathrm{~s}^{-1}\right]$, as:

$$
v_{\text {motility }}=-\mu_{e f f} \frac{\partial b}{\partial x}
$$

290 The effective random motility coefficient is dependent on the viscosity of the fluid in the

291 hepatopancreatic duct, $\eta_{h}$ [mPa.s], and is described as follows(23):

$$
\mu_{e f f}=\mu_{0}\left(\frac{\eta_{w}}{\eta_{h}}\right)^{2}
$$

$293 \eta_{w}[\mathrm{mPa} \cdot \mathrm{s}]$ is the viscosity of water. Therefore, the viscosity in the hepatopancreatic duct should

294 be lower than that in bile or pancreatic juice as they are diluted there, as calculated using the

295 viscosity of pancreatic juice, $\eta_{p}$ [mPa.s], pancreatic juice flow, $U_{p}\left[\mathrm{ml} \mathrm{min}^{-1}\right]$ and bile flow rate,

$296 Q_{b}\left[\mathrm{ml} \mathrm{min}^{-1}\right]$ as:

$$
\eta_{h}=\frac{Q_{p}}{Q_{p}+Q_{b}} \eta_{p}
$$

298 This is based on the assumption that pancreatic juice and bile acid contribute to viscosity

299 independently. This is justified as pancreatic juice viscosity is due to enzymatic proteins, while the 300 viscous contribution of bile is due to bile acids. Using parameters of viscosity of pancreatic juice

301 of $1.5 \mathrm{mPa} \cdot \mathrm{s}(51)$, bile flow rate at $0.43 \mathrm{ml} \mathrm{min}^{-1}$, and pancreatic juice flow rate at $0.2 \mathrm{ml} \mathrm{min}^{-1}$

302 (table S2), the viscosity due to pancreatic juice is at $0.95 \mathrm{mPa} \cdot \mathrm{s}$ (eqn. 4). The viscosity of bile at

$3030.90 \mathrm{mPa} \cdot \mathrm{s}(52)$ is lower than that $(0.95 \mathrm{mPa} \cdot \mathrm{s})$. Thus, a viscosity of $0.95 \mathrm{mPa} \cdot \mathrm{s}$ is used for that in

304 the hepatopancreatic duct. Pancreatic tissues are considered porous media, and the random 
305 motility coefficient in pancreatic tissues is described using tortuosity $\tau$ [-] and porosity $\phi[-]$ as 306 follows:

$$
D_{e f f}^{O_{2}}=D_{0}^{O_{2}} \frac{\eta_{w}}{\eta_{h}} \cdot \frac{\phi}{\tau}\left(0<r<r_{h}\right)
$$

308

309 Bacterial transport across the wall of the duct is described using permeability of the duct of

310 bacteria, $P_{b}\left[\mathrm{~m} \mathrm{~s}^{-1}\right]$ as follows:

$$
\operatorname{Flux}_{b}\left(r=r_{h}\right)=P_{b}\left\{b\left(r=r_{h}\right)_{\text {wall }}-b\left(r=r_{h}\right)_{d u c t}\right\}
$$

312 where $b\left(r=r_{h}\right)_{\text {wall }}$ and $b\left(r=r_{h}\right)_{d u c t}$ are bacterial concentrations on the ductal wall in the duodenum

313 wall and hepatopancreatic duct, respectively. $r_{h}[\mathrm{~mm}]$ is the radius of the hepato-pancreatic duct.

314 Note the unit of flux is CFU m$~_{-2} \mathrm{~s}^{-1}$. The permeability of the bile duct for bacteria was determined

315 from measurements in rats in the literature. The permeability of the human bile duct is estimated

316 using a bile duct wall thickness of $80 \mu \mathrm{m}$ in mice(53) and that in humans at $0.5 \mathrm{~mm}(54)$

\subsubsection{Aerotaxis}

$$
\text { Bacteria monitor their cellular energy levels and respond to a decrease in energy by }
$$

320 swimming to a microenvironment that reenergizes the cells(55). Thus, bacteria migrate toward

321 optimal oxygen and carbon dioxide levels for better energy production by using a strategy called

322 "energy taxis" (56). Additionally, carbon dioxide also works as an attractant or repellent, although

323 less is known about this. Adult Caenorhabditis elegans display an acute avoidance response

324 upon exposure to $\mathrm{CO}_{2}(57,58)$. The facultative anaerobe Oscillatoria migrated away from air to 325 carbon dioxide (32). 
326 In aerotaxis, bacteria use sensing mechanisms called 'logarithmic sensing,' where bacteria sense

327 the logarithm of the concentration gradient(59). A modified Keller-Segel model, Lapidus and

328 Schiller model(60), is used for logarithmic sensing of the aerotactic term for oxygen in Eqn. (7):

$$
V_{a}^{x}=\chi_{0}^{a} \frac{K_{d}}{\left(K_{d}+a\right)^{2}} \cdot \frac{\partial a}{\partial x}
$$

330 where $a\left[\mathrm{~mol} \mathrm{I}^{-1}\right]$ is the oxygen concentration, $\chi_{0}^{a}\left[\mathrm{~m}^{2} \mathrm{~s}^{-1}\right]$ is the chemotactic sensitivity

331 coefficient of bacterial aerotaxis, and $K_{d}\left[\mathrm{mmol} \mathrm{I}^{-1}\right]$ is the dissociation constant. Note that

332 aerotactic velocity is independent of viscosity(61). Aerotaxis away from higher carbon dioxide is

333 described in:

$$
V_{c}^{x}=-\chi_{0}^{c} \frac{1}{\left(K_{d}^{c}+c\right)} \cdot \frac{\partial c}{\partial x}
$$

$335 K_{d}^{c}[\mathrm{mmol} /]$ is the dissociation constant for the ligand and receptor for carbon dioxide. A typical

336 chemotactic sensitivity coefficient of $1 \times 10^{-8} \mathrm{~m}^{2} \mathrm{~s}^{-1}$ is used.

340 mechanisms for cytoplasmic $\mathrm{pH}$ homeostasis to survive and, in some cases, grow during

341 exposure to acidic or alkaline conditions that are well outside the $\mathrm{pH}$ range tolerated for

342 cytoplasmic $\mathrm{pH}(62-64)$. A sensing mechanism is called 'pH taxis', a bidirectional behavior that

343 migrates away from extremely acidic and alkaline environments and to optimal $\mathrm{pH}$.

344 A continuum-based mathematical model for bacterial $\mathrm{pH}$ taxis is developed here based on a

345 traditional chemotaxis Keller-Segel (K-S) model. Chemotactic velocity, $V_{c}[\mathrm{~m} / \mathrm{s}]$, is proportional to

346 the logarithm of the chemoattractant (or chemorepellent) concentration gradient, as described in 
$347 \quad V_{c}=\chi / c \cdot \partial c / \partial x$, where $c[\mathrm{~mol} / \mathrm{l}]$ is the chemoattractant or chemorepellent

348 concentration and $\chi\left[\mathrm{m}^{2} \mathrm{~s}^{-1}\right]$ is the chemotactic sensitivity coefficient. However, this equation

349 cannot be applied to $\mathrm{pH}$ taxis, as $\mathrm{pH}$-tactic bacteria exhibit bidirectional behavior, i.e., away from

350 alkaline and acidic $\mathrm{pH}$ toward neutral $\mathrm{pH}$. Therefore, we modified the $\mathrm{K}-\mathrm{S}$ model so that bacteria

351 can sense the logarithm of "differences of concentration from optimal concentration", as

352 described in the following:

$$
V_{p H}^{x}=\chi_{0}^{p H} \frac{d\left(\ln \left(\left[H^{+}\right]-\left[H^{+}\right]_{0}\right)\right)}{d x}=\chi_{0}^{p H} \frac{1}{\left(\left[H^{+}\right]-\left[H^{+}\right]_{0}\right)} \cdot \frac{d\left(\left[H^{+}\right]\right)}{d x}
$$

354 where $\left[\mathrm{H}^{+}\right]_{0}$ is the optimal hydrogen ion concentration for bacteria, $\left[\mathrm{H}^{+}\right]$is the hydrogen ion

355 concentration, and $\mathcal{X}_{\mathrm{O}}^{p H}\left[\mathrm{~m}^{2} \mathrm{~s}^{-1}\right]$ is the $\mathrm{pH}$-tactic sensitivity coefficient.

356 This model was validated against the measured distribution of Serratia marcescens under a pH

357 gradient by Zuang and coworkers with their permissions(63). Motility and $\mathrm{pH}$-tactic contributions

358 were calculated from the difference in distribution density of bacteria for motility contribution and

359 eqn. (5) for $\mathrm{pH}$-taxis, respectively. The optimal $\mathrm{pH}$ for $\mathrm{S}$. marcescens, $\mathrm{pH}_{0}$ at 7.2 , is used from the

360 study. In the steady state, the ratio of motility to $\mathrm{pH}$-taxis contribution is constant, as described in

361 the following equation:

$$
\frac{d b}{d x}=-\frac{\chi_{0}^{p H}}{\mu} \cdot \underbrace{\frac{1}{\left(\left[H^{+}\right]-\left[H^{+}\right]_{\text {opt }}\right)} \cdot \frac{d\left(\left[H^{+}\right]\right)}{d x} b}_{\mathrm{pH}-\text { tactic contribution }}
$$

363 This equation is obtained from eqn. (1) for the one-dimensional case without flow $(v=0)$ or

364 aeortaxis $\left(\chi_{\mathrm{O}}^{\text {aero }}=\mathrm{O}\right)$. The motility and $\mathrm{pH}$-tactic contribution calculated from data in the 365 literature are shown in Figure S12 when the probability density of bacteria, $\rho$, was used in place 366 of $b$ in eqn. (10). The contribution of motility was reasonably well correlated with the $\mathrm{pH}$-taxis 
contribution in the literature (63) with correlation coefficients of 0.89 and 0.91 for $\mathrm{pH}<7.2$ and $\mathrm{pH}$

$368>7.2$ (figure S12), validating the model. The parameter of the chemotactic sensitivity coefficient,

$369 \chi_{0}^{p H}\left[\mathrm{~m}^{2} \mathrm{~s}^{-1}\right]$, was calculated from the slope of Figure $\mathrm{S} 12, k$, which is equal to the ratio of the

370 chemotactic sensitivity coefficient to the random motility coefficient from Eqn. (10):

$$
k=\frac{\chi_{0}^{p H}}{\mu_{0}}
$$

372 These coefficients, $k$, are 65.1 and -35.2 for $\mathrm{pH}<7.2$ and $\mathrm{pH}>7.2$, respectively. From a given

373 random motility coefficient, the chemotactic sensitivity coefficient of $\mathrm{pH}$ taxis is determined.

374 Ion equilibrium and transport

375 Pancreatic juice contains bicarbonate, $\mathrm{HCO}_{3}^{-}$, at approximately $80 \mathrm{mmol} \mathrm{I}^{-1}$ in the fasted

376 state(65), and this bicarbonate neutralizes gastric acid in the duodenum in the following two

377 equilibrium equations:

$$
\mathrm{H}^{+}+\mathrm{HCO}_{3}^{-} \rightleftarrows \mathrm{H}_{2} \mathrm{CO}_{3}
$$

$$
\mathrm{H}_{2} \mathrm{CO}_{3} \rightleftarrows \mathrm{H}_{2} \mathrm{O}+\mathrm{CO}_{2}
$$

380 These reactions can be written in a single equilibrium equation:

$$
\mathrm{H}^{+}+\mathrm{HCO}_{3}^{-} \stackrel{k+}{\stackrel{k-}{\rightleftarrows}} \mathrm{H}_{2} \mathrm{O}+\mathrm{CO}_{2}
$$

382 Equilibrium equations in eqns. (12) and (13) are described using dissociation constants $K_{1}\left[\mathrm{~mol} \mathrm{I}^{-}\right.$ $\left.383{ }^{1}\right]$ and $K_{2}[-]$ :

$$
\frac{\left[\mathrm{H}^{+}\right]\left[\mathrm{HCO}_{3}^{-}\right]}{\left[\mathrm{H}_{2} \mathrm{CO}_{3}\right]}=K_{1}
$$

$$
\frac{\left[\mathrm{H}_{2} \mathrm{CO}_{3}\right]}{p C \mathrm{O}_{2}}=K_{2}
$$


These are summarized in:

$$
\frac{\left[\mathrm{H}^{+}\right]\left[\mathrm{HCO}_{3}^{-}\right]}{p C \mathrm{O}_{2}}=\frac{k_{-}}{k_{+}}=K_{1} K_{2}=K^{*}
$$

$388 K^{*}=10^{-6.1} \mathrm{~mol} \mathrm{l}^{-1}$ and $K_{-}=3.71 \times 10^{-2} \mathrm{~s}^{-1}$ from the literature(66). Note eqn. (17) can be rewritten in 389 a simple manner:

$$
p H=p K^{*}+\ln \frac{\left[\mathrm{CO}_{2}\right]}{\left[\mathrm{HCO}_{3}^{-}\right]}
$$

391 The transport of hydrogen ions in the duct is described with reaction terms as follows:

$$
\frac{\partial\left[H^{+}\right]}{\partial t}=\underbrace{D_{\text {eff }}^{H+}\left(\frac{\partial^{2}\left[H^{+}\right]}{\partial x^{2}}+\frac{\partial^{2}\left[H^{+}\right]}{\partial r^{2}}+\frac{1}{r} \frac{\partial\left[H^{+}\right]}{\partial r}\right)}_{\text {diffusion }} \underbrace{\frac{\partial}{\partial x}\left(u_{h}\left[H^{+}\right]\right)}_{\begin{array}{c}
\text { bile and } \\
\text { pancreatic juice flow }
\end{array}} \underbrace{-k_{+}\left[H^{+}\right]\left[\mathrm{HCO}_{3}^{-}\right]+k_{-}\left[\mathrm{CO}_{2}\right]}_{\text {reactions }}
$$

393 Diffusion across the ductal wall at $r=r_{h}$ is described using permeability as follows:

$$
\operatorname{Flux}_{H^{+}}=P_{H^{+}}\left(\left[H^{+}\right]_{r=r_{h}}^{\text {wall }}-\left[H^{+}\right]_{r=r_{h}}^{d u c t}\right)
$$

395 where $\boldsymbol{P}_{\boldsymbol{H}^{+}}\left[\mathrm{m} \mathrm{s}^{-1}\right]$ is the ductal permeability of hydrogen ions. $\left[\boldsymbol{H}^{+}\right]_{r=r_{h}}^{\text {wall }}$ and

$396\left[\mathrm{H}^{+}\right]_{r=r_{h}}^{d u c t}\left[\mathrm{~mol} \mathrm{I}^{-1}\right]$ are the hydrogen ion concentrations on the ductal wall in the duodenum

397 and hepatopancreatic duct, respectively. The concentrations of bicarbonate and carbon dioxide in

398 the duct, $\left[\mathrm{HCO}_{3}^{-}\right]$and $\left[\mathrm{CO}_{2}\right]\left[\mathrm{mol} \mathrm{I}^{-1}\right]$, are also described in the same manner as:

$$
\frac{\partial\left[\mathrm{HCO}_{3}^{-}\right]}{\partial t}=\underbrace{D_{e f f}^{\mathrm{HCO}-}\left(\frac{\partial^{2}\left[\mathrm{HCO}_{3}^{-}\right]}{\partial x^{2}}+\frac{\partial^{2}\left[\mathrm{HCO}_{3}^{-}\right]}{\partial r^{2}}+\frac{1}{r} \frac{\partial\left[\mathrm{HCO}_{3}^{-}\right]}{\partial r}\right)}_{\text {diffusion }} \underbrace{-\frac{\partial}{\partial x}\left(u_{h}\left[\mathrm{HCO}_{3}^{-}\right]\right)}_{\begin{array}{c}
\text { bile end } \\
\text { pancreatic juice flow }
\end{array}} \underbrace{-k_{+}\left[\mathrm{H}^{+}\right]\left[\mathrm{HCO}_{3}^{-}\right]+k_{-}\left[\mathrm{CO}_{2}\right]}_{\text {reactions }}
$$

$$
\frac{\partial\left[\mathrm{CO}_{2}\right]}{\partial t}=\underbrace{D_{\text {eff }}^{\mathrm{CO} 2}\left(\frac{\partial^{2}\left[\mathrm{CO}_{2}\right]}{\partial x^{2}}+\frac{\partial^{2}\left[\mathrm{CO}_{2}\right]}{\partial r^{2}}+\frac{1}{r} \frac{\partial\left[\mathrm{CO}_{2}\right]}{\partial r}\right)}_{\text {diffusion }} \underbrace{-\frac{\partial}{\partial x}\left(u_{h}\left[\mathrm{CO}_{2}\right]\right.}_{\begin{array}{c}
\text { bile and } \\
\text { pancreatic juice flow }
\end{array}} \underbrace{+k_{+}\left[\mathrm{H}^{+}\right]\left[\mathrm{HCO}_{3}^{-}\right]-k_{-}\left[\mathrm{CO}_{2}\right]}_{\text {reactions }}
$$


The bile duct and pancreatic duct joints together at the distal pancreas, consisting of a

404 hepatopancreatic duct or common channel $1-11 \mathrm{~mm}$ in length $(67,68)$, open in the duodenum.

405 Thus, fluid flow in the hepatopancreatic duct is caused by both bile and pancreatic juice. Bile and

406 pancreatic juice flow rates were calculated from daily total bile flow at $620 \mathrm{ml} \mathrm{day}^{-1}\left(0.43 \mathrm{ml} \mathrm{min}^{-}\right.$

$\left.407{ }^{1}\right)(69)$, and the pancreatic juice flow rate during the fasted state was $0.2-0.3 \mathrm{ml} \mathrm{min}^{-1}$. The flow

408 rate of a fasted period is used here, as migration should be more straightforward during this

409 period, when bile and pancreatic juice secretions are lower (70). Additionally, duodenal pH is

410 faster in the fasted period. The volumetric flow rate in the hepatopancreatic duct, $Q_{h}[\mathrm{ml} / \mathrm{min}]$, is

411 thus calculated as follows:

$$
Q_{h}=Q_{p}+Q_{b}
$$

413 The Reynolds number in the hepatopancreatic duct was calculated using the following equation:

$$
\operatorname{Re}=\frac{\rho Q_{h}}{\eta_{h} A}
$$

$415 A\left[\mathrm{~m}^{2}\right]$ is the cross-sectional area of the duct. The volumetric flow rate in the hepatopancreatic

416 duct of healthy individuals, $Q_{h}\left[\mathrm{~m}^{3} \mathrm{~s}^{-1}\right]$, is $0.63 \mathrm{ml} \mathrm{min}^{-1}$. Thus, the Reynolds number in the

417 hepatopancreatic duct was calculated to be 0.52 , assuring laminar flow. Thus, the fluid velocities

418 follow the Hagen-Poiseuille law as:

$$
v_{h}(r)=v_{\max }\left\{1-\left(\frac{r}{r_{h}}\right)^{2}\right\}
$$

$420 v_{h}(r)$ is the fluid velocity at the ductal radius of $r[\mathrm{~mm}]$, and $r_{h}[\mathrm{~mm}]$ is the radius of the

421 hepatopancreatic duct. The maximum flow velocity, $v_{\max }\left[\mathrm{m} \mathrm{s}^{-1}\right]$, is calculated as: 


$$
v_{\max }=\frac{2 Q_{h}}{\pi r_{h}^{2}}
$$

423 The maximum flow velocity in the hepatopancreatic duct for a healthy individual is $494 \mu \mathrm{m} \mathrm{s}^{-1}$.

424 The pancreatic juice flow rate of pancreatic cancer patients is $1 / 4$ that of healthy individuals in the 425 literature(21. The flow rate of bile for cancer patients is missing in the literature. Therefore, the

426 flow rate of patients with obstruction due to bile stones at $56-373 \mathrm{ml} / \mathrm{day}(212 \mathrm{ml} / \mathrm{day}$ on

427 average) (71is used for cancer patients. The maximum flow rate in the duct for cancer patients is 428 calculated at $126 \mu \mathrm{m} \mathrm{s}^{-1}$.

\subsection{Oxygen transport}

Oxygen transport in the hepatopancreatic duct, duodenal wall, and pancreatic tissues is mathematically modeled and includes diffusion and flow in the hepatopancreatic duct, as

433 described in the following equation:

$$
\frac{\partial a}{\partial t}=\underbrace{D_{e f f}^{O_{2}}\left(\frac{\partial^{2} a}{\partial x^{2}}+\frac{\partial^{2} a}{\partial r^{2}}+\frac{1}{r} \frac{\partial a}{\partial r}\right)}_{\text {diffusion }} \underbrace{-\frac{\partial}{\partial x}\left(v_{h} a\right)}_{\begin{array}{c}
\text { bile and } \\
\text { pancreatic juice flow }
\end{array}}
$$

435 where $a\left[\mathrm{~mol} \mathrm{I}^{-1}\right]$ is the oxygen concentration, $D_{\text {eff }}{ }^{\mathrm{O}}\left[\mathrm{m}^{2} \mathrm{~s}^{-1}\right]$ is the effective diffusion coefficient of 436 oxygen in the hepatopancreatic duct, and pancreatic tissues are considered porous media. The 437 effective diffusion coefficient of oxygen is thus described as:

$$
D_{e f f}^{O_{2}}=D_{0}^{O_{2}} \frac{\eta_{w}}{\eta_{h}} \cdot \frac{\phi}{\tau}\left(0<r<r_{h}\right)
$$

$439 D_{0}\left[\mathrm{~m}^{2} \mathrm{~s}^{-1}\right]$ is the diffusion coefficient of oxygen in water at $37^{\circ} \mathrm{C}, \eta_{w}[\mathrm{mPa} \cdot \mathrm{s}]$ is the viscosity of

440 water, $\eta_{h}[\mathrm{mPa} \cdot \mathrm{s}]$ is the viscosity of fluid in the hepatopancreatic duct, $\phi[-]$ is porosity and $\tau$

441 [-] is tortuosity. Therefore, the flux of oxygen across the hepatopancreatic duct is also described 442 as follows: 


$$
F l u x=P_{o 2}\left(a_{r=r_{h}}^{\text {wall }}-a_{r=r_{h}}^{d u c t}\right)
$$

444 Oxygen transport is not included in the healthy pancreas, assuming no oxygen concentration

445 difference between healthy pancreas and duodenum, but was included for transport in the

446 pancreas with tumor since oxygen concentration in the pancreatic tumor is lower due to rapid

447 oxygen consumption by cancer cells.

4494.3 Boundary conditions and numerical simulations

450 The governing equations were numerically solved using COMSOL Multiphysics 5.0 with initial and 451 boundary conditions as follows. The bacterial concentration in duodenum fluid at $10^{4} \mathrm{CFU} \mathrm{ml}^{-1}$ 452 was used for the boundary condition(72:

$$
b(x=0)=10^{4} \mathrm{CFU} \mathrm{ml}^{-1}
$$

454 The oxygen concentration in the human duodenum is not available in the literature. The oxygen 455 concentration in the stomach is $58 \mathrm{mmHg}$ in mice, while that in the duodenum is $32 \mathrm{mmHg}(73)$

456 Oxygen level in the human stomach is at $15-16 \%(74)$. Using this ratio of oxygen concentration in 457 mice and equilibrium the oxygen concentration to air at $37^{\circ} \mathrm{C}$ at $0.21 \mathrm{mmol}^{-1}$, oxygen 458 concentration in duodenum at $0.083 \mathrm{mmol} \mathrm{I}^{-1}$ is used. Oxygen concentration in tumors at 15 $459 \mathrm{mmHg}$ is also used(75)

$$
a(x=0)=0.083 \mathrm{mmol} \mathrm{l}^{-1}
$$

$$
a\left(x=x_{d}\right)=0.039 \mathrm{mmol} \mathrm{l}^{-1}
$$

462 The distance between the duodenum and pancreatic tumor did not affect the oxygen

463 concentration gradient between the duodenum and the pancreatic tumor in preliminary simulation 464 studies. The $\mathrm{pH}$ of fasted human duodenum at 4.9 is used (39) 


$$
p H(x=0)=4.9
$$

466 An initial carbon dioxide concentration of $5 \%(2.64 \mathrm{mmol} / \mathrm{l})$ was used.

$$
\left[\mathrm{CO}_{2}\right]_{0}(t=0)=2.64 \mathrm{mmol} / 1
$$

468 The bicarbonate concentration in pancreatic juice during the fasting period is $80 \mathrm{mmol} \mathrm{I}^{-1}(57)$.

$$
\left[\mathrm{HCO}_{3}^{-}\right]_{0}(t=0)=80 \mathrm{mmol} / 1
$$

5. Experimental methods

A polydimethylsiloxane (PDMS) microfluidic device that can generate a steady

474 concentration gradient using double-layered flow was fabricated (figure S12). PDMS elastomer 475 base (SILPOT ${ }^{\mathrm{TM}} 184$ Silicone Elastomer Base) was mixed with a curing agent (SILPOT ${ }^{\mathrm{TM}} 184$

476 Silicone Elastomer Curing Agent) at a ratio of 10:1. The PDMS mixture was degassed using a 477 vacuum chamber (G-20DA, ULVAC KIKO. Inc., Japan). The degassed mixture was poured onto 478 the metal mold, designed for the device and created previously, and cured by heating at $75^{\circ} \mathrm{C}$ for 479 two hours. Then, PDMS was peeled off of the metal mold. Both surfaces of the PDMS microfluidic 480 device and a sliding glass were irradiated with oxygen plasma (SEDE-P, meiwafosis, Japan) at 48110 pascals at $5 \mathrm{~mA}$ for 35 seconds. Both were attached to each other and heated at $90^{\circ} \mathrm{C}$ for one 482 hour to permanently bond. 
489 minutes. The bacterial pellet was then washed in distilled water and centrifuged again. The pellet 490 was then diluted into hydrochloride or bicarbonate solution.

491 Syringe pumps (Aladdin 1000, US) were connected to this microfluidic device. Bicarbonate (80 $492 \mathrm{mmol} / \mathrm{l})$ and hydrochloride $\left(10^{-3} \mathrm{~mol} / \mathrm{l}\right)$ solutions were poured at $200 \mu \mathrm{l} / \mathrm{min}$ from inlets 1 and 2 , 493 respectively (figure 2a). GFP E. coli were included in either of them. Bacterial distribution was 494 measured from the fluorescence of GFP E. coli under irradiation with UV light (350 nm) using a 495 digital single lens reflex (D5100, Nikon, Japan) in black-and-white mode. The $\mathrm{pH}$ in the

496 microfluidic channel was visualized using bromothymol blue solution (figure 2a) or 497 phenolphthalein solution (Sigma Aldrich, Japan) (figure S2). The obtained images were analyzed 498 using ImageJ (NIH, US). The relative brightness was calculated as $\left(B_{\max }-B\right) /\left(B_{\max }-B_{\min }\right)$.

502 solution or sodium bicarbonate under bicarbonate solution flow was analyzed using a T-shaped

503 cylinder fabricated by referring to previous literature(76). First, the degassed mixture of PDMS

504 was poured into a 12-mm diameter petri dish with a thickness of a few millimeters (figure S15a).

505 This PDMS mixture was cured at $75^{\circ} \mathrm{C}$ for two hours as a basis for the cylinder. Then, glass tubes

506 were placed in T-shaped tubes, and another PDMS mixture was poured there (Figure S15b, c).

507 The tubes were then removed carefully by incising with a cutter, leaving a hollow T-shaped

508 cylinder (figure S15d). End tips of the hollowed cylinders were filled with remaining cured PDMS

509 so that the PDMS that would be poured later would not be filled in. Finally, the PDMS mixture was

510 poured into the whole device and cured (figure S15e).

511 Five-milliliter syringes filled with hydrochloride (approximately $10^{-4.9} \mathrm{~mol} / \mathrm{l}$ ) or sodium bicarbonate

$512(80 \mathrm{mmol} / \mathrm{l})$ solution containing bacteria were connected to the upper inlet of the T-shaped

513 cylinder. Bacteria in hydrochloride solution were prepared by diluting the bacterial pellet obtained

514 by centrifugation with hydrochloride at the desired concentration. The $\mathrm{pH}$ was adjusted by the 
515 color of bromocresol purple (Wako Chem., Japan). This concentration of hydrochloride is chosen

516 because that of fasted duodenum is at 4.9-5.5(39). The flow rates were $200 \mu \mathrm{l} / \mathrm{min}$ and $20 \mu \mathrm{l} / \mathrm{min}$.

517 The $\mathrm{pH}$ distribution was measured by bromocresol purple (FujifilmWako, Japan). Bacteria were

518 measured in the same manner as Sec. 5.1, but movies were taken using a CMOS image sensor

519 (IMX586, Sony, Japan). The obtained movies were analyzed using MATLAB 2021 (MathWorks,

520 Japan), as shown in Figure S16. Horizontal distance in millimeters was calculated from a ruler in

521 an image placed near the device.

524 Acknowledgments

525 This research is financially supported by the Keio Gijuku Academic Development Funds for

526 multidisciplinary Research (2019). We acknowledge the provision of data for $\mathrm{pH}$ taxis by Prof.

527 Mertin Sitti of the Max Planck Institute. We acknowledge discussions with Dr. Masayasu Horibe

528 and Dr. Eisuke Iwasaki of School of Medicine, Department of Internal Medicine (Gastroenterology

529 and Hepatology) of Keio University. We acknowledge the Keio University manufacturing center

530 for creating the metal mold for the microfluidic device.

531

532

\section{References}

534 1. Rawla P, Sunkara T, Gaduputi V (2019) Epidemiology of Pancreatic Cancer: Global Trends, $535 \quad$ Etiology and Risk Factors. World J. Oncol. 10(1):10-27.

536 2. Gopalakrishnan V, et al. (2018) Gut microbiome modulates response to anti-PD-1

537 immunotherapy in melanoma patients. Science, 359(6371):97-103.

538 3. Gaiser RA, et al. (2019) Enrichment of oral microbiota in early cystic precursors to invasive 539 pancreatic cancer. Gut 68(12):2186-2194.

540 4. Li, S., G.M. Fuhler, N. BN, T. Jose, M.J. Bruno, M.P. Peppelenbosch, and S.R.

541 Konstantinov. (2017). Pancreatic cyst fluid harbors a unique microbiome. Microbiome. 5. 
542 5. Lillioja S, Mott DM, Spraul M, Ferraro R, Foley JE, R.E. et al. (1993). The New England

543 Journal of Medicine. Massachusetts Medical Society. All rights reserved. N. Engl. J. Med. 29:

$544 \quad 1230-5$.

545 6. Schmid, S.W., W. Uhl, H. Friess, P. Malfertheiner, and M.W. Büchler. (1999). The role of $546 \quad$ infection in acute pancreatitis. Gut. 45: 311-316.

547 7. Thomas, R.M. et al. (2018). Intestinal microbiota enhances pancreatic carcinogenesis in $548 \quad$ preclinical models. Carcinogenesis. 39: 1068-1078.

549 8. Guo, W., Y. et al. (2021). Tumor microbiome contributes to an aggressive phenotype in the $550 \quad$ basal-like subtype of pancreatic cancer. Commun. Biol. 4: 1-13.

551 9. Nejman D, et al. (2020) The human tumor microbiome is composed of tumor type-specific $552 \quad$ intracellular bacteria. Science, 368(6494):973-980.

553 10. Geller LT, et al. (2017) Potential role of intratumor bacteria in mediating tumor resistance to 554 the chemotherapeutic drug gemcitabine. Science;357(6356):1156-1160.

555 11. Thomas RM, Jobin C (2020) Microbiota in pancreatic health and disease: the next frontier in $556 \quad$ microbiome research. Nat Rev Gastroenterol Hepatol 17(1):53-64.

557 12. Pushalkar S, et al. (2018) The pancreatic cancer microbiome promotes oncogenesis by 558 induction of innate and adaptive immune suppression. Cancer Discov 8(4):403-416.

559 13. Riquelme E, et al. (2019) Tumor Microbiome Diversity and Composition Influence Pancreatic $560 \quad$ Cancer Outcomes. Cell 178(4):795-806.e12.

561 14. Chandra, V., and F. McAllister. (2021). Therapeutic potential of microbial modulation in 562 pancreatic cancer. Gut. 70: 1419-1425.

563 15. Ezenobi NO, Okpokwasili GC (2016) Combined effect of temperature and pH on $564 \quad$ Pseudomonas aeruginosa isolated from a cosmetic product. Int. J. Curr. Res. 8(08):37124$565 \quad 37130$.

566 16. Gunasekaran V, Kotay SM, Das D (2006) Alkaline lipase production by Citrobacter freundii $567 \quad$ IIT-BT L139. Indian J Exp Biol 44(6):485-491.

568 17. Abbas SZ, et al. (2014) Isolation and characterization of arsenic resistant bacteria from 569 wastewater. Brazilian J Microbiol 45(4):1309-1315. 
570 18. Beal C, Louvet $\mathrm{P}$, Corrieu G (1989) Influence of controlled pH and temperature on the 571 growth and acidification of pure cultures of Streptococcus thermophilus 404 and $572 \quad$ Lactobacillus bulgaricus 398. Appl Microbiol Biotechnol 32(2):148-154.

573 19. Nakano S, et al. (2020) Association between the use of antibiotics and efficacy of 574 gemcitabine plus nab-paclitaxel in advanced pancreatic cancer. Medicine (Baltimore)

575 20. Imai H, et al. (2019) Antibiotic therapy augments the efficacy of gemcitabine-containing 576 regimens for advanced cancer: A retrospective study. Cancer Manag Res 11:7953-7965.

577 21. Del Castillo E, et al. (2019) The microbiomes of pancreatic and duodenum tissue overlap 578 and are highly subject specific but differ between pancreatic cancer and noncancer subjects. $579 \quad$ Cancer Epidemiol Biomarkers Prev 28(2):370-383.

580 22. Ranjbaran, M., and A.K. Datta. (2021). Engineering modeling frameworks for microbial food $581 \quad$ safety at various scales.: $1-37$.

582 23. Shirai H, Datta AK, Oshita S (2017) Penetration of aerobic bacteria into meat : A mechanistic $583 \quad$ understanding. J Food Eng 196:193-207.

584 24. Ranjbaran, M., and A.K. Datta. (2019). Retention and infiltration of bacteria on a plant leaf 585 driven by surface water evaporation. Phys. Fluids. 31: 112106.

586 25. Figueroa-Morales N, Dominguez-Rubio L, Ott TL, Aranson IS (2019) Mechanical shear controls bacterial penetration in mucus. Sci Rep 9(1):1-10.

588 26. Matilla MA, Krell T. The effect of bacterial chemotaxis on host infection and pathogenicity. $589 \quad$ FEMS Microbiol Rev. 2018 Jan 1;42(1).

590 27. Kaya T, Koser H (2012) Direct upstream motility in Escherichia coli. Biophys J 102(7):1514$591 \quad 1523$.

592 28. Marcos, H.C. Fu, T.R. Powers, and R. Stocker. (2012). Bacterial rheotaxis. Proc. Natl. Acad. $593 \quad$ Sci. U. S. A. 109: 4780-4785.

594 29. Figueroa-Morales N, et al. (2020) E. Coli "supercontaminates" narrow ducts fostered by 595 broad run-time distribution. Sci Adv 6(11):1-8.Marcos, Fu HC, Powers TR, Stocker R (2012) $596 \quad$ Bacterial rheotaxis. Proc Natl Acad Sci U S A 109(13):4780-4785. 
597 30. Diao J, et al. (2006) A three-channel microfluidic device for generating static linear gradients 598 and its application to the quantitative analysis of bacterial chemotaxis. Lab Chip 6(3):381$599 \quad 388$.

600 31. Sung JY, Costerton JW, Shaffer EA (1992) Defense system in the biliary tract against 601 bacterial infection. Dig Dis Sci 37(5):689-696.

602 32. G, Walsby AE (1985) Chemotaxis of a cyanobacterium on concentration gradients of carbon 603 dioxide, bicarbonate and oxygen. J Gen Microbiol 131(10):2643-2652.

604 33. Rinderknecht H, Renner IG, Stace NH (1983) Abnormalities in pancreatic secretory profiles 605 of patients with cancer of the pancreas. Dig Dis Sci 28(2):103-110.

606 34. Carr-Locke DL (1980) Serum and pancreatic juice carcinoembryonic antigen in pancreatic 607 and biliary disease. Gut 21(8):656-661.

608 35. Gregg JA, Sharma MM (1978) Endoscopic measurement of pancreatic juice secretory flow 609 rates and pancreatic secretory pressures after secretin administration in human controls and 610 in patients with acute relapsing pancreatitis, chronic pancreatitis, and pancreatic cancer. Am $611 \quad$ J Surg 136(5):569-574.

612 36. Kruse EJ. Palliation in pancreatic cancer. Surg Clin North Am. 2010 Apr;90(2):355-64.

613 37. Muir CA (2004) Acute ascending cholangitis. Clin J Oncol Nurs 8(2):157-160.

614 38. Guyton AC. Human physiology and mechanism of disease. 1987: 499.

615 39. Ovesen L, et al. (1986) Intraluminal pH in the stomach, duodenum, and proximal jejunum in 616 normal subjects and patients with exocrine pancreatic insufficiency. Gastroenterology $61790(4): 958-962$.

618 40. Bhattacharjee, T., and S.S. Datta. (2019). Bacterial hopping and trapping in porous media. $619 \quad$ Nat. Commun. 10.

620 41. Westphal, K., S. Leschner, J. Jablonska, H. Loessner, and S. Weiss. Containment of tumor621 colonizing bacteria by host neutrophils. Cancer Res. 68: 2952-2960.2008.

622 42. Abdeldayem, H., E. Ghoneim, A.A.-E. Refaei, and A. Abou-Gabal. Obstructive jaundice 623 promotes intestinal-barrier dysfunction and bacterial translocation: experimental study.

$624 \quad$ Hepatol. Int. 1: 444-448.2007. 
625 43. Fan, X. et al. (2018). Human oral microbiome and prospective risk for pancreatic cancer: A 626 population-based nested case-control study. Gut. 67: 120-127.

627 44. Yoshida, H., M. et al. (2019). Coadministration of magnesium oxide reduces the serum 628 concentration of hydrophobic basic drugs in patients treated with antipsychotic drugs. Biol. $629 \quad$ Pharm. Bull. 42: 1025-1029.

630 45. Bovo, P., G. et al. (1995). Intraluminal gastric pH in chronic pancreatitis. Gut. 36: 294-298.

631 46. Chauhan, V.P. et al. (2013). Angiotensin inhibition enhances drug delivery and potentiates 632 chemotherapy by decompressing tumor blood vessels. Nat. Commun. 4.

633 47. National Library of Medicine (U.S.). (2005, March - Fecal Microbial Transplants for the 634 Treatment of Pancreatic Cancer. Identifier NCT04975217.

635 48. Danino, T., A. et al.(2015). Programmable probiotics for detection of cancer in urine. Sci. $636 \quad$ Transl. Med. 7.

637 49. Chowdhury, S. et al. (2019). Programmable bacteria induce durable tumor regression and 638 systemic antitumor immunity. Nat. Med. 25: 1057-1063.

639 50. Keller EF, Segel LA (1971) Model for chemotaxis. J Theor Biol 30(2):225-234.

640 51. Harada H, Ueda O, Kochi F, Kobayashi T, Komazawa M. Comparative studies on viscosity 641 and concentration of protein and hexosamine in pure pancreatic juice. Gastroenterol Jpn. $642 \quad 1981 \mathrm{Dec} ; 16(6): 623-6$.

643 52. Reinhart WH, Näf G, Werth B (2010) Viscosity of human bile sampled from the common bile 644 duct. Clin Hemorheol Microcirc 44(3):177-182.

645 53. Smith D, Boyer L (1982) Permeability characteristics of bile duct in the rat. Am J Physiol. $646 \quad$ Jan;242(1):G52-7.

647 54. Testoni PA, et al. (2006) Main pancreatic duct, common bile duct and sphincter of Oddi 648 structure visualized by optical coherence tomography: An ex vivo study compared with 649 histology. Dig Liver Dis 38(6):409-414.

650 55. Taylor BL, Zhulin IB, Johnson MS (1999) Aerotaxis and other energy-sensing behavior in 651 bacteria. Annu Rev Microbiol 53:103-128. 
652 56. Taylor BL (1983) How do bacteria find the optimal concentration of oxygen? Trends Biochem 653 Sci 8(12):438-441.

654 57. Bretscher AJ, Busch KE, De Bono M (2008) A carbon dioxide avoidance behavior is

655 integrated with responses to ambient oxygen and food in Caenorhabditis elegans. Proc Natl $656 \quad$ Acad Sci U S A 105(23):8044-8049

657 58. Hallem EA, Sternberg PW (2008) Acute carbon dioxide avoidance in Caenorhabditis $658 \quad$ elegans. Proc Natl Acad Sci U S A 105(23):8038-8043.

659 59. Menolascina F, et al. (2017) Logarithmic sensing in Bacillus subtilis aerotaxis. Npj Syst Biol $660 \quad$ App/3(June):16036.

661 60. Lapidus IR, Schiller R (1976) Model for the chemotactic response of a bacterial population. $662 \quad$ Biophys J 16(12):779-789.

663 61. Schauer O, et al. (2018) Motility and chemotaxis of bacteria-driven microswimmers 664 fabricated using antigen 43-mediated biotin display. Sci Rep 8(1):1-11. Krulwich TA, Sachs 665 G, Padan E (2011) Molecular aspects of bacterial pH sensing and homeostasis. Nat Rev $666 \quad$ Microbiol 9(5):330-343.

667 62. Yang Y, Sourjik V (2012) Opposite responses by different chemoreceptors set a tunable 668 preference point in Escherichia coli pH taxis. Mol Microbiol 86(6):1482-1489.

669 63. Zhuang J, Carlsen RW, Sitti M (2015) PH-taxis of biohybrid microsystems. Sci Rep 5:1-13.

670 64. Hu B, Tu Y (2014) Behaviors and Strategies of Bacterial Navigation in Chemical and $671 \quad$ Nonchemical Gradients. PLoS Comput Biol 10(6):e1003672.

672 65. Gerolami A, et al. (1989) Calcium Carbonate Saturation in Human Pancreatic juice: Possible 673 Role of Ductal H+ Secretion. Gastroenterology 96(2):881-884.

674 66. Schulz KG, Riebesell U, Rost B, Thoms S, Zeebe RE (2006) Determination of the rate 675 constants for the carbon dioxide to bicarbonate interconversion in $\mathrm{pH}$-buffered seawater $676 \quad$ systems. Mar Chem 100(1-2):53-65.

677 67. Higashiyama H, et al. (2016) Anatomy of the Murine Hepatobiliary System: A Whole-Organ678 Level Analysis Using a Transparency Method. Anat Rec 299(2):161-172. 
679 68. Higashiyama $\mathrm{H}$, et al. (2018) Anatomy and development of the extrahepatic biliary system in 680 mouse and rat: a perspective on the evolutionary loss of the gallbladder. $J$ Anat 232(1):134$681 \quad 145$.

682 69. Esteller A (2008) Physiology of bile secretion. World J Gastroenterol 14(37):5641-5649.

683 70. Glasbrenner B, Dürrschnabel L, Büchler M, Malfertheiner P (1992) Nonparallel patterns of 684 circadian pancreatic and biliary secretions in fasting rats. Int J Pancreatol 11(3):169-177.

685 71. Ohya, T., Murakami, E., Kougame, A., Numata, Y., and Hiraoka, M. (2013). Proposal of 686 endoscopic lithotripsy for common bile duct stones based on the pathogenesis of stone 687 formation. Cholithiasis. Ann Surgery 238 (1), 97-102 in Japanese.

688 72. Sender R, Fuchs S, Milo R (2016) Revised Estimates for the Number of Human and Bacteria $689 \quad$ Cells in the Body. PLoS Biol 14(8):1-14.

690 73. He G, et al. (1999) Noninvasive measurement of anatomic structure and intraluminal 691 oxygenation in the gastrointestinal tract of living mice with spatial and spectral EPR imaging.

$692 \quad$ Proc Natl Acad Sci U S A 96(8):4586-4591.

693 74. Britannica Health \& Medicine, Anatomy \& Physiology Intestinal gas.

694 https://www.britannica.com/science/intestinal-gas Accessed Dec.18 ${ }^{\text {th }}, 2020$.

695 75. Matsumoto S, et al. (2018) Metabolic and physiologic imaging biomarkers of the tumor 696 microenvironment predict treatment outcome with radiation or a hypoxia-activated prodrug in 697 mice. Cancer Res 78(14):3783-3792.

698 76. Pauty J, et al. (2018) A Vascular Endothelial Growth Factor-Dependent Sprouting 699 Angiogenesis Assay Based on an In Vitro Human Blood Vessel Model for the Study of Anti$700 \quad$ Angiogenic Drugs. EBioMedicine 27:225-236.

701 77. Spadoni, I., E. et al. (2015). A gut-vascular barrier controls the systemic dissemination of $702 \quad$ bacteria. Science. 350: 830-834.

703 


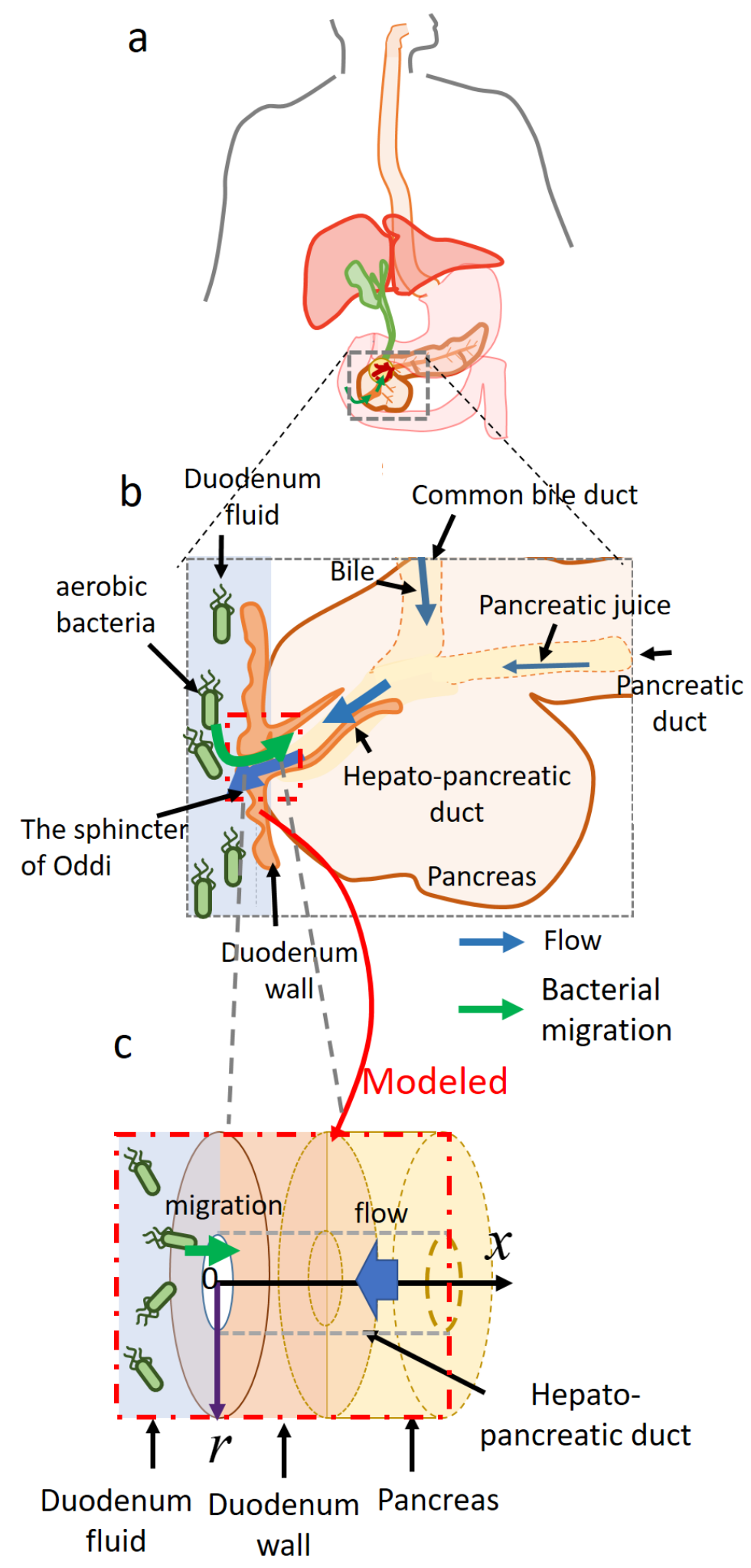


707 Figure 1. A schematic of the anatomy of the upper gastrointestinal tract (a) and a magnification of 708 the duodenum and pancreas (b). c: Geometry used for mathematical modeling of bacterial 709 migration.

710 
(a)

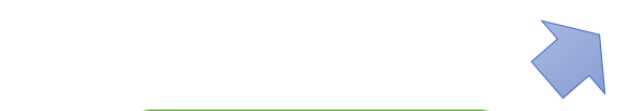

$(\mathrm{a}, \mathrm{b})$

Bile salt

secretion

(c)

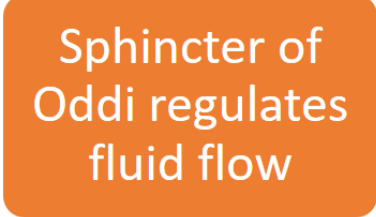

(d)

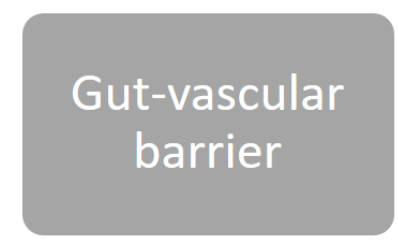

(b)
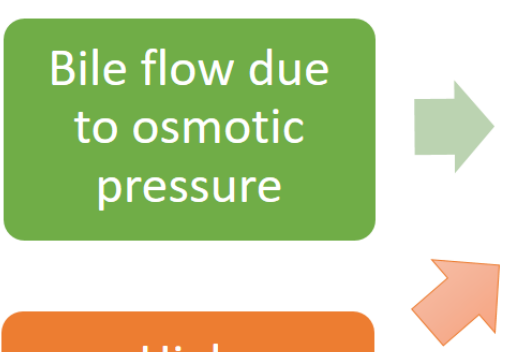

High

hydrostatic

pressure

\section{Prohibited}

migration into

portal vein
Prohibited

bacterial

proliferation

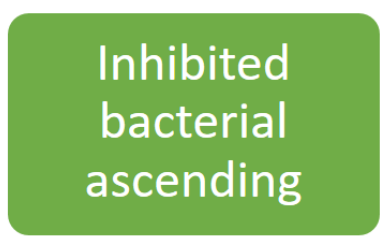

Inhibited

migration to

pancreas

712 Figure 2. Defense mechanisms against bacterial invasion from the intestine into the pancreas(31,

713 77). Hydrophobic bile salts prohibit bacterial proliferation (a). Bile and pancreatic juice flow

714 prohibits bacterial invasion (a). The sphincter of Oddi, a muscle situated at the junction of the

715 biliary tract and duodenum, controls the flow of bile and pancreatic juice; the high-pressure zone

716 here prevents reflux of bacteria in the duodenum into the biliary tract(31) (c). The gut-vascular

717 barrier also controls the translocation of antigens and thus prevents the translocation of bacteria

718 from the gut through the portal vein to the liver or pancreas(77) (d). 


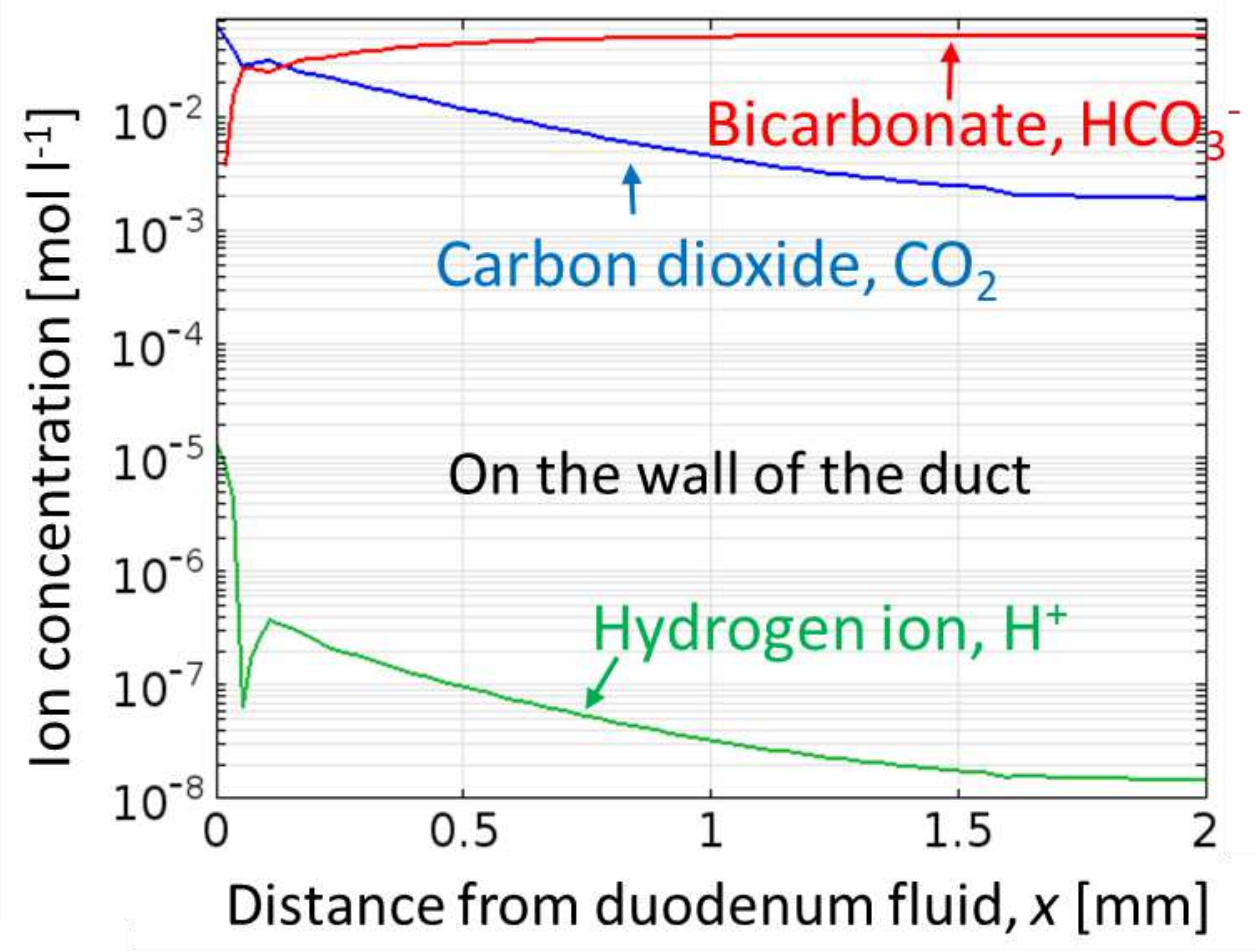

722

723 Figure 3. Simulated $\mathrm{pH}$ increased greatly between duodenal fluid and the pancreatic duct (a,

724 green), as hydrogen ions (b green) were neutralized by bicarbonate ( $\mathbf{b}$ red) with carbon dioxide

725 as a byproduct (b blue). Simulated ion concentration distribution in the hepatopancreatic duct of

726 healthy individuals. Ion concentrations at a ductal radius of $4.1 \mathrm{~mm}$ (b)

$p H=-\log _{10}\left(\left[H^{+}\right]\right)$ 


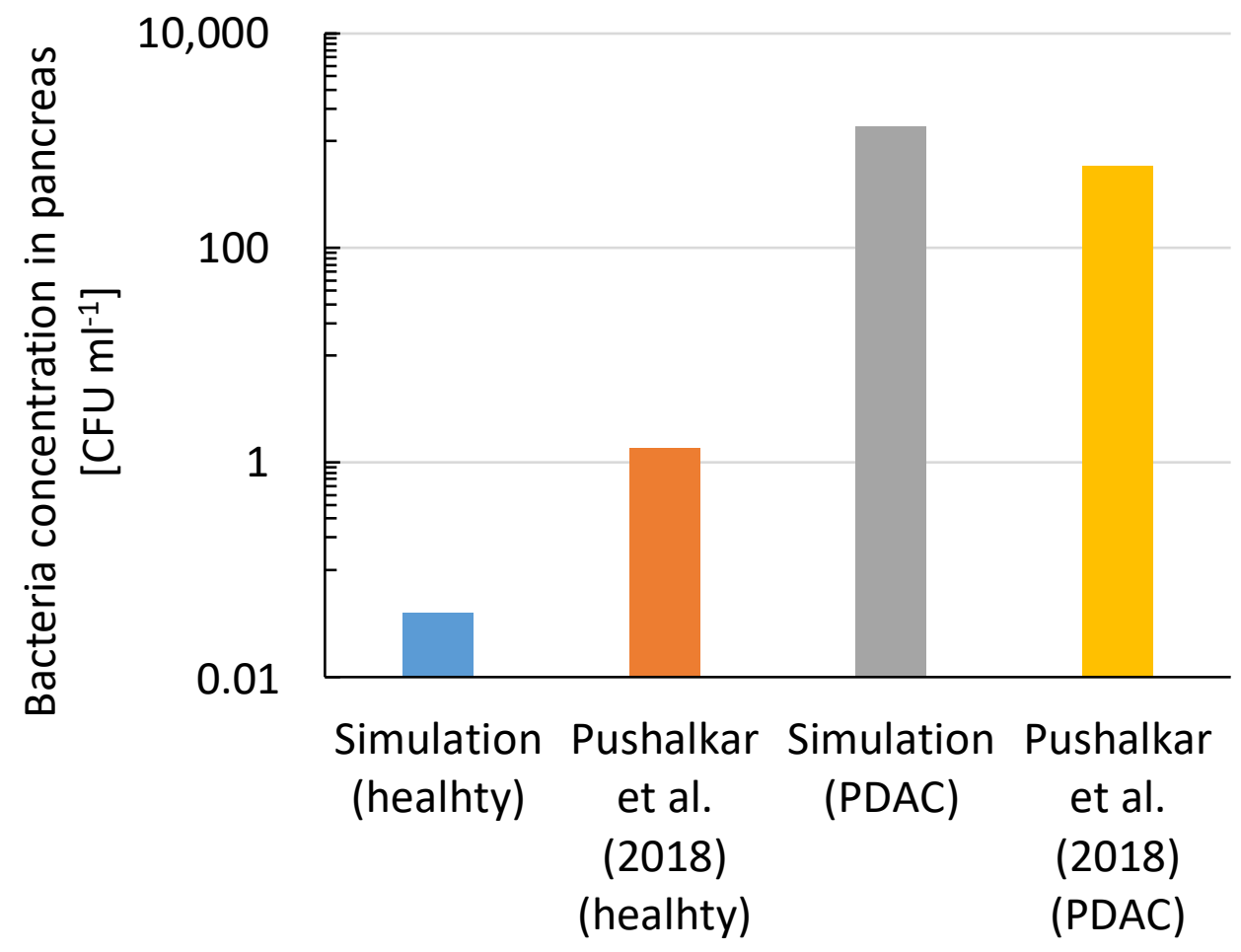

728

729 Figure 4. The simulated bacterial concentration in the healthy pancreas is lower than that in the

730 literature (blue), but that in the pancreas with tumors (green) agrees reasonably well with the

731 literature(10) (green). The literature value was calculated using the DNA weight of E. coli at 17

732 fg/cell(2). PDAC: pancreatic ductal adenocarcinoma

733 
a. $\mathrm{pH}$

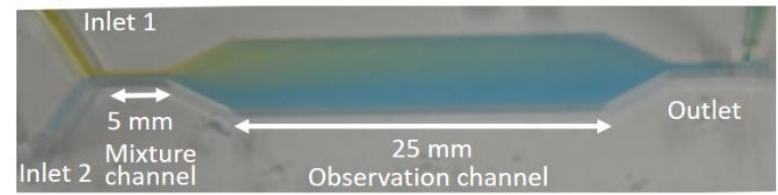

b. GFP E.coli from acid (from upper inlet)

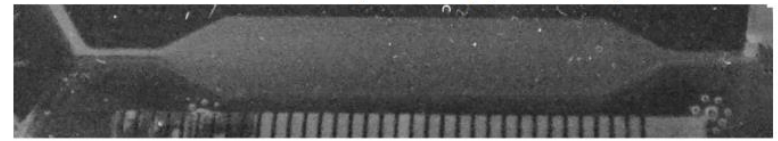

c. GFP E.coli from bicarbonate (from lower inlet)

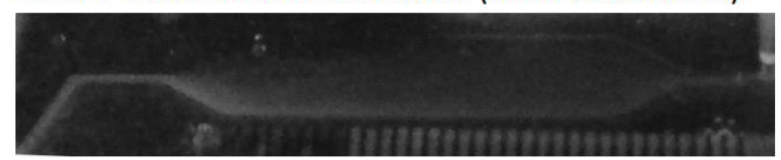

d. GFP E. coli without gradient (from lower inlet)

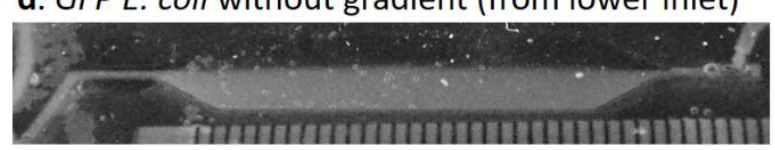

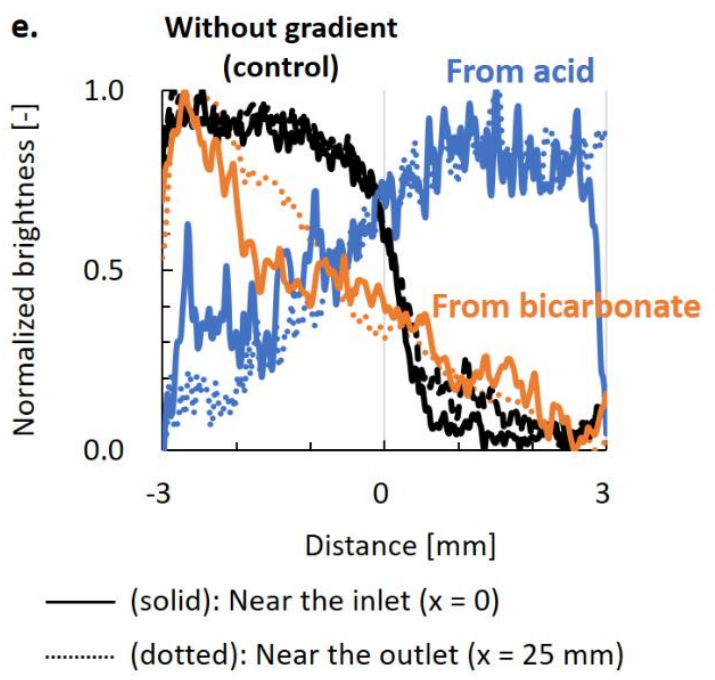

Figure 5. A steady $\mathrm{pH}$ gradient is generated in a microfluidic device, where the $\mathrm{pH}$ increases from

$737 \quad 5-6$ at the top to $7-8$ at the bottom (a). GFP E. coli were attracted away from the upper channel

738 with a lower $\mathrm{pH}$ toward the lower part with neutral $\mathrm{pH}$ due to $\mathrm{pH}$ taxis (b, $\mathbf{c}, \mathbf{e}$ blue and orange). a:

$739 \mathrm{pH}$ was visualized in bromothymol blue. b, c: Bacteria were included in either the upper inlet (b)

740 or the lower inlet (c). d: GFP E.coli migrated little without gradient. e: Distribution of GFP E. coli in

741 the proximal (dotted) and distal (solid) channels. Photos in $\mathbf{b}-\mathbf{d}$ were taken in black-and-white

742 mode under black light at $350 \mathrm{~nm}$.

743

744

745 
pH distribution

\section{P. fluorescens +}

a hydrochloride, $200 \mu \mathrm{l} / \mathrm{min}$

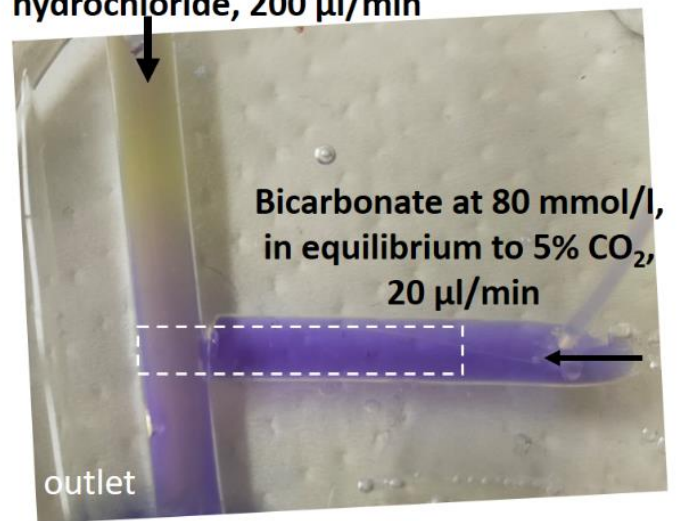

Bacterial distribution over time

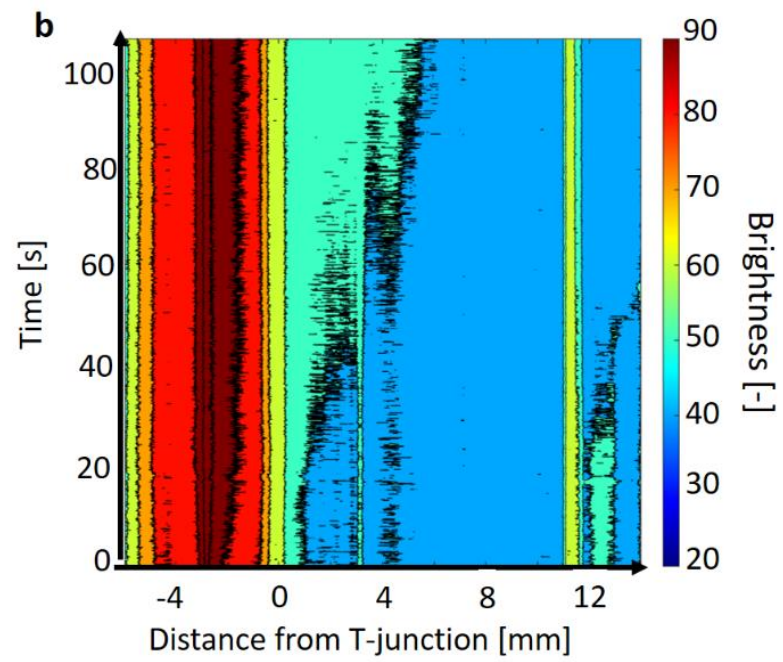

747 Figure 6. Measured upstream migrations of $P$. fluorescens against the flow of bicarbonate with a

748 maximum fluid velocity of $52 \mu \mathrm{m} / \mathrm{s}$ from hydrochloride solution in a simply fabricated PDMS T-

749 shaped cylinder. a: $\mathrm{pH}$ in the T-shaped cylinder, visualized in bromocresol purple. The $\mathrm{pH}$

750 increased from 5-6 in dark yellow at top to neutral in purple at right. b: Bacterial distribution over

751 time in the white-dotted areas in a. $P$. fluorescens migrated upstream against flow under this $\mathrm{pH}$

752 gradient (a) with a penetration rate of approximately $50 \mu \mathrm{m} / \mathrm{s}$. 


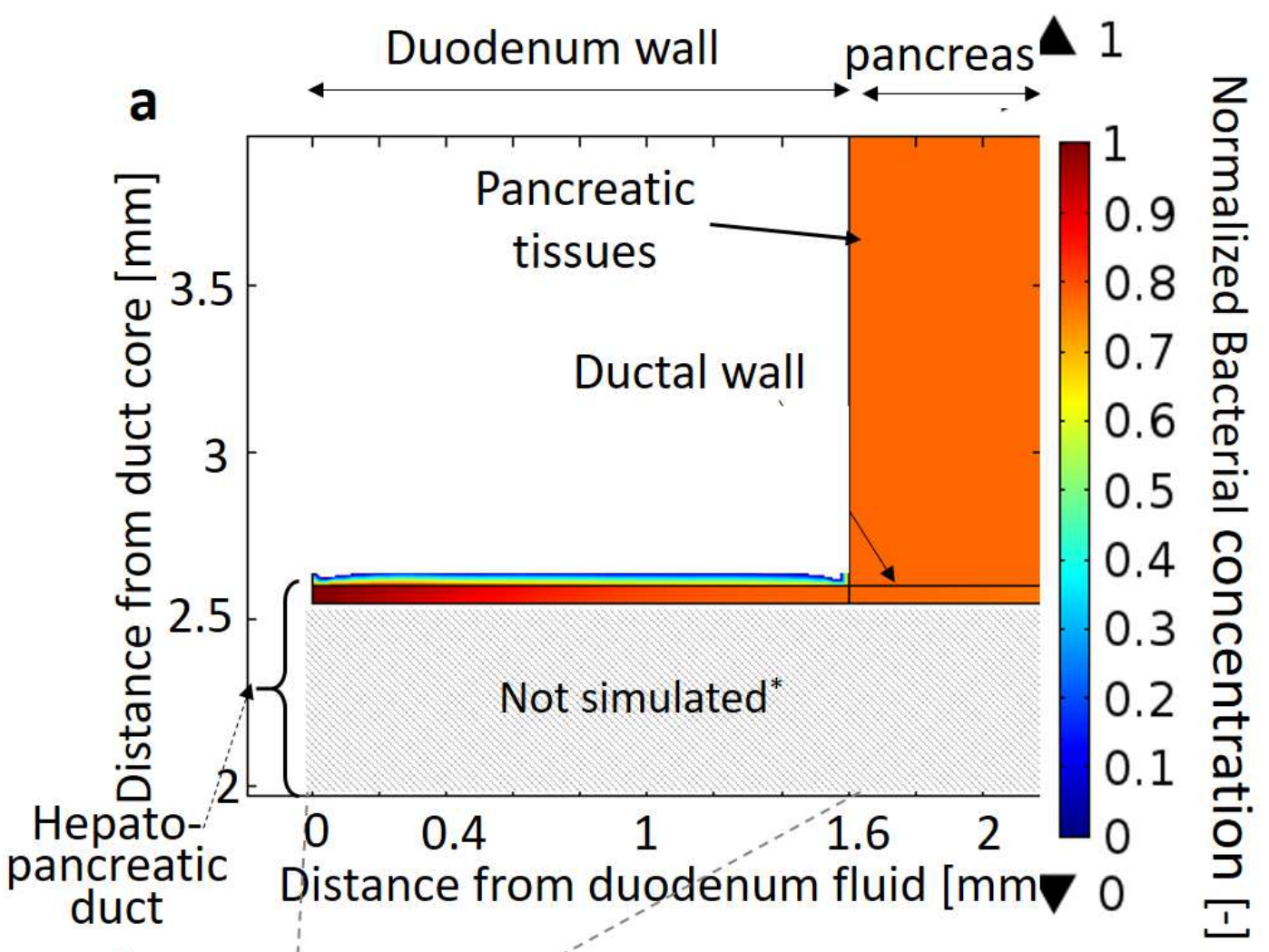

b

755 Figure 7. Migration of aerobic bacteria from the duodenum to the pancreas with tumors in the 
756 hepatopancreatic duct is made easier by reduced pancreatic juice and bile flow rate due to

757 obstructions of the pancreatic and bile duct by solid tumors

758 


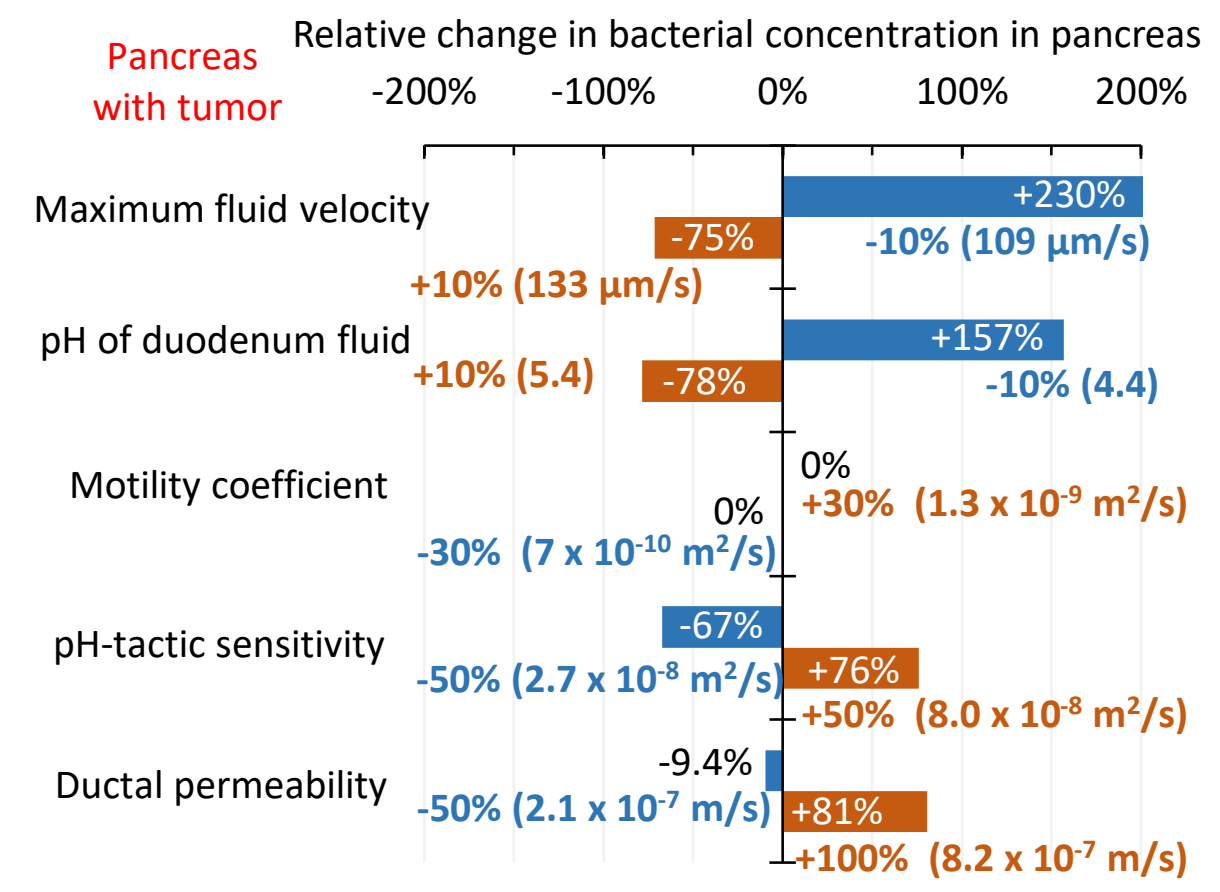

759

760 Figure 8. Parametric sensitivity analysis for bacterial migration from the duodenum into the 761 pancreas with tumors.

762 
- Reduced pancreatic juice secretion ${ }^{33-35}$

- Cholangitis in cancer patients ${ }^{37}$

- Bacterial accumulation in tumor ${ }^{10,12}$

Anti-biotics ${ }^{10,19,20}$, FMT to influence tumor microbiome $e^{13,48}$

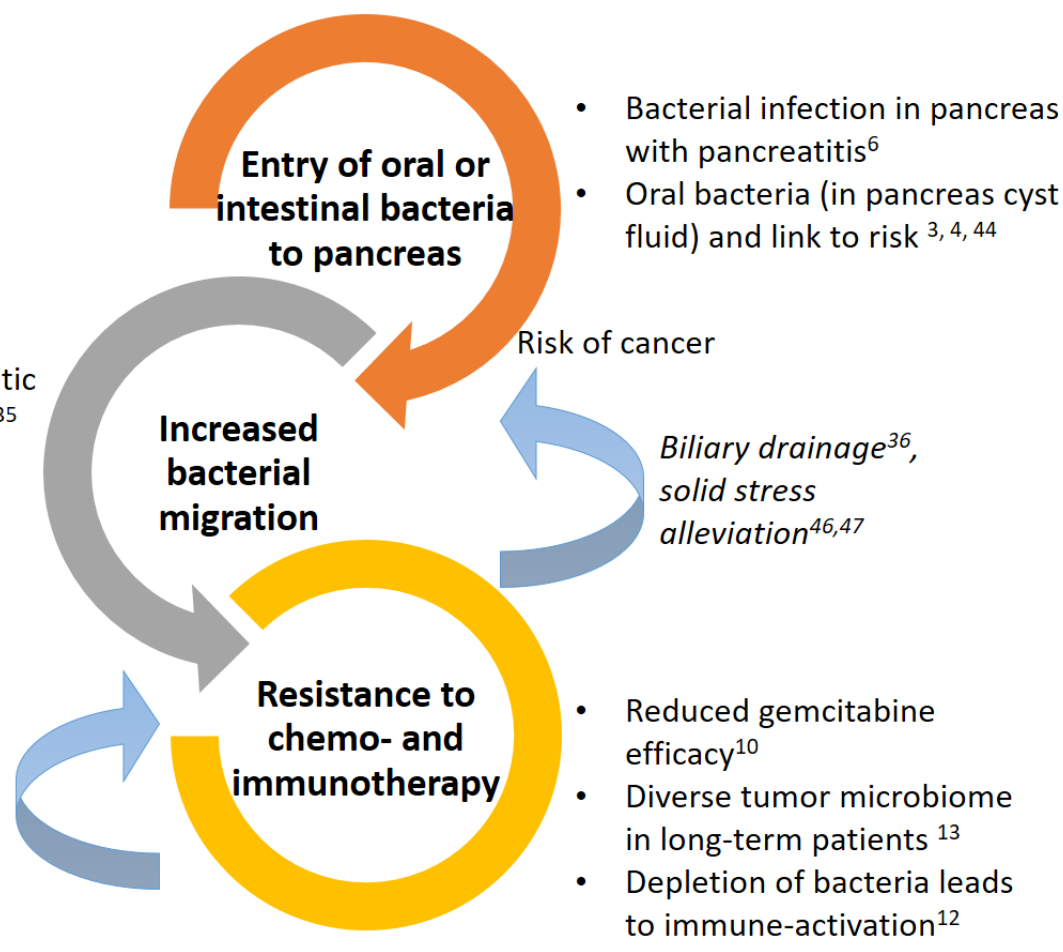

765 Figure 9. Hypothetical overview of involvement of oral or intestinal bacterial migration in risk, 766 diseases, and resistance to treatment, with potential solutions. 


\section{Environmental factors}

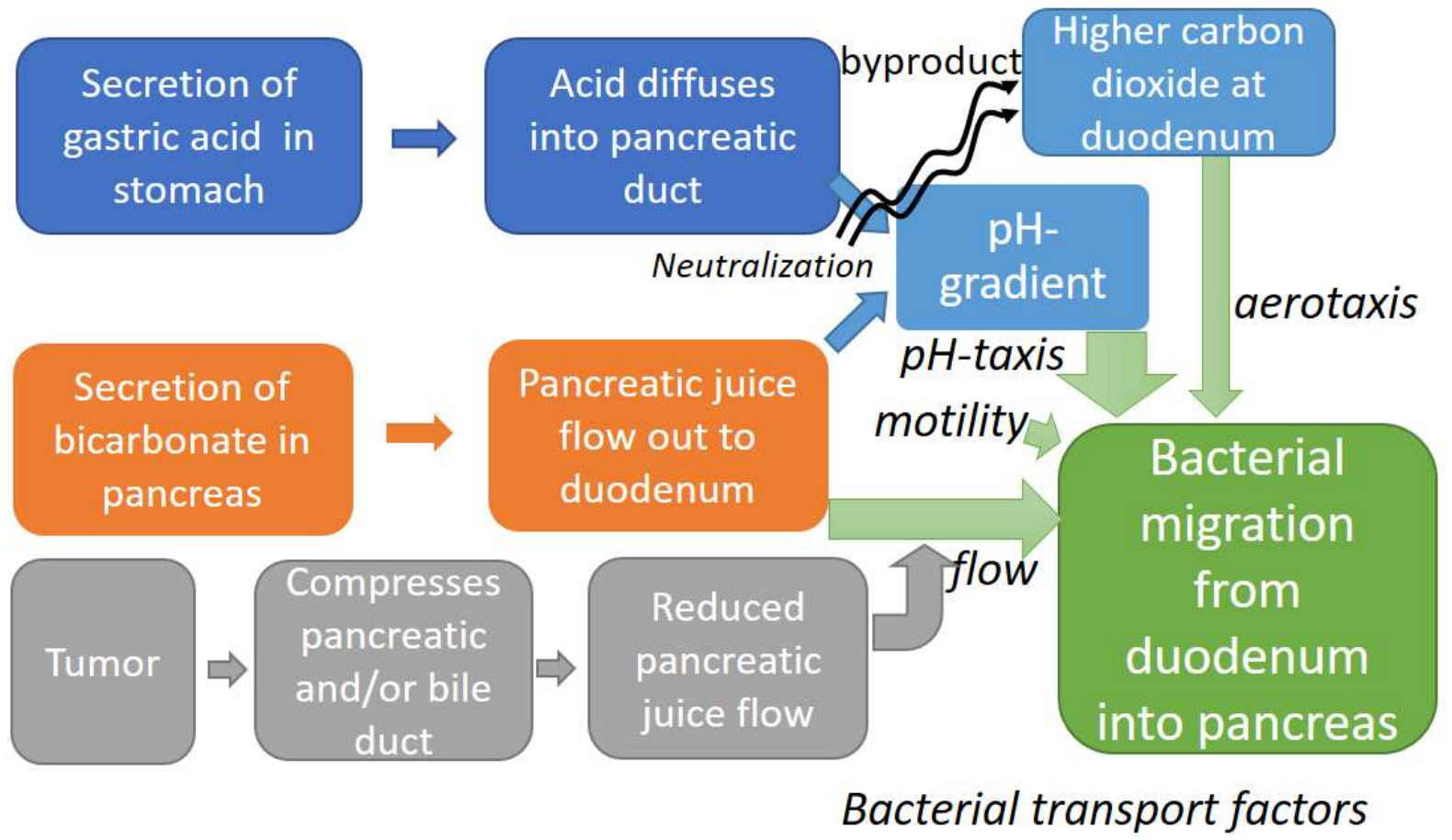

768

769 Figure 10. Environmental factors in the upper gastrointestinal tract affect the migration of aerobic

770 bacteria from the duodenum into the pancreas.

771

772

773 
774 Table 1. List of the factors that influence transports included in this work

\begin{tabular}{cc}
\hline motility & $\begin{array}{c}\text { Diffusion-like run-and-tumble random motion using flagellar, increases } \\
\text { migration }\end{array}$ \\
chemotaxis & Migration toward chemoattractant or away from repellent \\
Aerotaxis & $\begin{array}{c}\text { Energy taxis, toward higher oxygen (duodenum) (decreases migration) } \\
\text { and away from higher carbon dioxide (duodenum) (increases } \\
\text { migration) (for aerobes) }\end{array}$ \\
& Migration from acid or alkaline pH toward neutral one, increases \\
\end{tabular}

775

776 


\section{Supplementary Files}

This is a list of supplementary files associated with this preprint. Click to download.

- supplemental1001edited2.zip 